\title{
Pharmacological Therapy in the Heart as an Alternative to Cellular Therapy: A Place for the Brain Natriuretic Peptide?
}

\author{
Nathalie Rosenblatt-Velin, ${ }^{1}$ Suzanne Badoux, ${ }^{1}$ and Lucas Liaudet ${ }^{2}$ \\ ${ }^{1}$ Division de Physiopathologie Clinique, Centre Hospitalier Universitaire Vaudois and University of Lausanne, \\ 1005 Lausanne, Switzerland \\ ${ }^{2}$ Service de Médecine Intensive Adulte, Centre Hospitalier Universitaire Vaudois and University of Lausanne, \\ 1005 Lausanne, Switzerland \\ Correspondence should be addressed to Nathalie Rosenblatt-Velin; nathalie.rosenblatt@chuv.ch
}

Received 18 June 2015; Revised 8 September 2015; Accepted 8 October 2015

Academic Editor: Kequan Guo

Copyright (C) 2016 Nathalie Rosenblatt-Velin et al. This is an open access article distributed under the Creative Commons Attribution License, which permits unrestricted use, distribution, and reproduction in any medium, provided the original work is properly cited.

\begin{abstract}
The discovery that stem cells isolated from different organs have the ability to differentiate into mature beating cardiomyocytes has fostered considerable interest in developing cellular regenerative therapies to treat cardiac diseases associated with the loss of viable myocardium. Clinical studies evaluating the potential of stem cells (from heart, blood, bone marrow, skeletal muscle, and fat) to regenerate the myocardium and improve its functional status indicated that although the method appeared generally safe, its overall efficacy has remained modest. Several issues raised by these studies were notably related to the nature and number of injected cells, as well as the route and timing of their administration, to cite only a few. Besides the direct administration of cardiac precursor cells, a distinct approach to cardiac regeneration could be based upon the stimulation of the heart's natural ability to regenerate, using pharmacological approaches. Indeed, differentiation and/or proliferation of cardiac precursor cells is controlled by various endogenous mediators, such as growth factors and cytokines, which could thus be used as pharmacological agents to promote regeneration. To illustrate such approach, we present recent results showing that the exogenous administration of the natriuretic peptide BNP triggers "endogenous" cardiac regeneration, following experimental myocardial infarction.
\end{abstract}

\section{Introduction}

Cardiovascular diseases (CVDs) account for $30 \%$ of all deaths worldwide, which represented 17.3 million fatalities in 2008 (World Health Organization, Fact sheet number 317), among which 13.5 million (80\%) were related to the consequences of coronary heart diseases (CHDs). This number is expected to rise steadily, with an estimated 23.3 million deaths in 2030 . The identified causes of this "epidemics" involve a sedentary life of style, an unhealthy diet, as well as the use of tobacco and/or alcohol consumption [1,2]. All favor the emergence of obesity, diabetes, and/or hypertension which are risk factors for CHDs.

Many efficient therapies have been developed to treat CVDs over the past 30 years, including various reperfusion strategies of occluded coronary vessels, antiplatelet and anticoagulant agents to prevent/treat coronary thrombosis, beta-blocking drugs, or angiotensin-converting enzyme inhibitors, to name only a few [3]. However, despite the identification of risk factors and the improvements in therapy, the morbidity and mortality associated with CHDs remain unacceptably high. A major reason for it is that CHDs induce the loss of a given amount of contractile myocardium, with unavoidable consequences on the functional activity of the heart. Indeed, the mammalian heart has long been considered a postmitotic organ with no capacity to regenerate [4], which is in striking contrast with certain lower vertebrates (zebrafish, urodeles), which have a high cardiac regeneration rate. The various treatments aimed to delay the onset of heart failure or to limit the consequences of CVDs, do not have the ability to replace the damaged cardiac cells, especially the necrotic and/or apoptotic cardiomyocytes [5], and thus 
cannot properly "heal" the injured heart. This view has begun to change dramatically with the discovery that the adult heart displays some capacity to regenerate after damage and, hence, that manipulating such regenerative capacity might have therapeutic potential. These emerging concepts will be here concisely reviewed.

\section{Regenerative Capacities of the Adult Mammalian Heart}

In the last decade, intensive research in the cardiovascular field has allowed a more precise understanding of the cellular and molecular mechanisms governing cardiomyocyte differentiation and proliferation during physiological growth, ageing, and pathophysiological conditions. A milestone observation was the demonstration that cardiac regeneration represents a physiological process occurring during ageing in normal conditions [6]. Although the proportion of newly formed cardiomyocytes is currently debated, the fact that new cardiomyocytes are generated in human hearts during physiological ageing and after heart injuries is now well admitted [6-8]. Different mechanisms have been identified to account for the de novo generation of cardiomyocytes in the adult heart. These mechanisms, detailed below, include the proliferation of the preexisting mature cardiomyocytes with or without dedifferentiation, the differentiation of endogenous precursor cells, and the differentiation of exogenous infiltrating cells (for review see [9]).

2.1. Proliferation of Mature Cardiomyocytes. Although cardiomyocytes in mammals demonstrate proliferative capacities during fetal development, it has been commonly admitted that after birth, cardiomyocytes cannot reenter the cell cycle, as DNA replication occurs without cytokinesis or karyokinesis [10]. This assumption was first challenged by the Sadek laboratory, who demonstrated that mouse cardiomyocytes can proliferate after partial surgical resection of the heart at birth [11]. In this mouse model, cardiomyocyte proliferation led to the replacement of the resected tissue and the inhibition of fibrosis. Notwithstanding this obvious regenerative process, the capacity of murine cardiomyocytes to proliferate was lost after 7 days of age. Further evidence of cardiomyocyte ability to proliferate came from the Lee laboratory, who recently proposed that preexisting cardiomyocytes represent the main source of newly formed cardiomyocytes during ageing, as well as following myocardial infarction (MI) [12]. However, although cardiomyocyte proliferation occurs life-long, this process is seldom in the mouse heart after the first month of life [13].

The mechanisms by which cardiomyocytes are able to proliferate are not well established. In zebrafish hearts, mature cardiomyocytes have to dedifferentiate before proliferating [14]. During this dedifferentiation, cardiomyocytes reduce their sarcomere structure (they become smaller and round) and reexpress the alpha skeletal actin ( $\alpha$-ska) protein as well as cardiac progenitor cell markers, such as Nkx2.5 and c-kit. They downregulate the expression of prototypical markers of mature cardiomyocytes, such as Troponin I and $\alpha$-myosin heavy chain $(\alpha-\mathrm{MHC})$. Their new structure and phenotype facilitate their reentry into the cell cycle. This process has also been observed in vitro in cardiomyocyte isolated from rat hearts [15]. However, whether this process occurs in vivo in mammal hearts is under debate. Dedifferentiated cardiomyocytes have been detected in the hearts of infarcted sheep hearts or in pressure-and-volume overloaded rabbit hearts $[16,17]$. In human hearts after idiopathic dilated cardiomyopathy, infarction or atrial fibrillation dedifferentiated cardiomyocytes were also detected $[18,19]$. The presence of these cells has been shown to be dependant at least in part by Oncostatin M [20]. However the results published until now did not demonstrate a direct link between the cardiomyocyte dedifferentiation and the proliferation. In other words, the results demonstrating that dedifferentiated cardiomyocytes proliferate in vivo are lacking.

However, stimulation of the cardiomyocyte proliferation appears as a new therapeutical strategy to increase cardiac regeneration especially in pathophysiological conditions. Several factors have been identified to be able to induce cardiomyocytes to reenter the cell cycle: Neuregulin 1 and its ERBB2 receptor [21-24], Periostin [25], the fibroblast growth factor-1 [26, 27], or also the stromal cell-derived factor $1 \alpha$ [28]. The use of miRNAs is also investigated and demonstrated that hsa-miR-590 and hsa-miR-199a were able to stimulate cardiomyocyte proliferation [29]. Interestingly, new results published by Sadek laboratory demonstrated that hypoxia is a crucial factor able to stimulate cardiomyocyte proliferation [30]. The authors identified in adult mouse hearts a small population of proliferating cardiomyocytes expressing Hif- $1 \alpha$ and able to give rise to new cardiomyocytes (at a rate of $0.3-1 \%$ per year) during physiological ageing. Thus, these results could explain why in neonatal hearts (relatively more hypoxic than adult hearts) cardiomyocytes proliferate. Thus, the oxygen postnatal environment which has been shown to lead to DNA damage response [31], appears as a major regulator of cardiomyocyte proliferation. However, the regulation of other genes such as p21 or the transcription factor Meis1 $[32,33]$ or the mechanical loading of the hearts [34] could also contribute to the arrest of cardiomyocyte proliferation in postnatal hearts.

2.2. Differentiation of Endogenous Precursor Cells. Cardiac precursor cells (CPCs), which have the capacity to differentiate into mature functional cardiomyocytes, exist in the heart itself. The characterization of these cells remains a difficult task, due to the lack of a defined, highly specific marker. Thus the association of several markers is required to identify cardiovascular progenitor and cardiac precursor cells [35, 36] (Figure 1). Early cardiogenic precursors originate from mesoderm and are identified as expressing the c-kit protein [37-39] (a cellular cytokine receptor initially found at the surface of hematopoietic progenitor cells), the vascular endothelial growth factor (VEGF) receptor 2 protein (Flk1) [40], and the nuclear transcription factor islet- $1[35,41$, 42]. These relative undifferentiated cells give rise to multipotent cardiovascular progenitors which express the nuclear transcription factor $\mathrm{Nkx} 2.5[43,44]$ together with the islet1, Flk-1, and c-kit proteins. These progenitors differentiate 


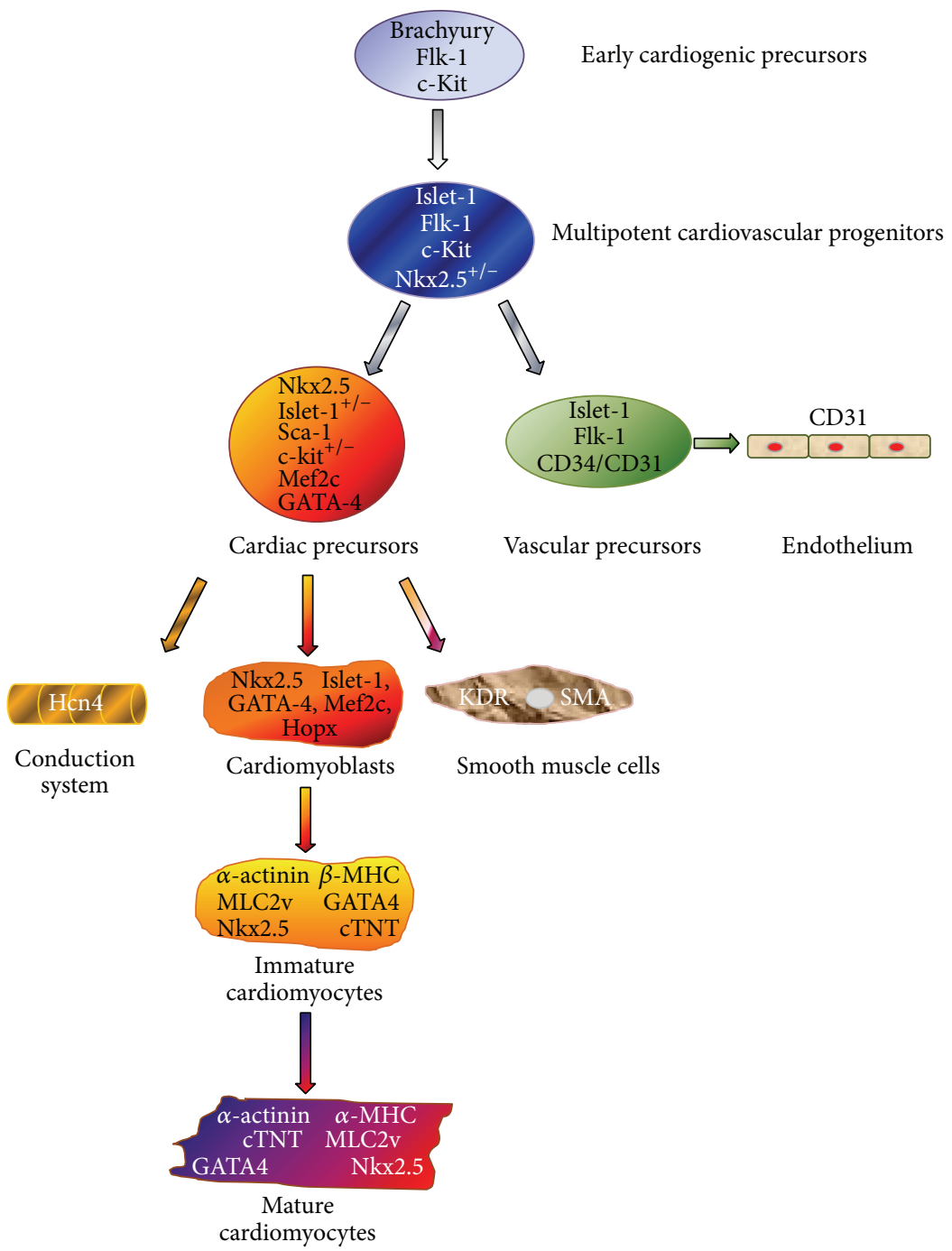

Figure 1: Cardiovascular cell lineage. Schematic representation depicting the origin of cardiomyocytes and endothelial and smooth muscle cells, as well as the conduction system. Several proteins are associated with the different stage of differentiation of the cardiac cells: islet-1, Flk-1, and c-kit are expressed at an undifferentiated stage, whereas the expression of Nkx2.5 and Sca-1 identifies more differentiated cardiac precursor cells.

into vascular precursors expressing the endothelial markers CD34 and CD31 or into cardiac precursor cells expressing notably Nkx2.5, GATA-4, Mef2c, and the stem cell antigen1 (Sca-1) proteins [42, 45-47]. CPCs can differentiate into cells of the conduction system, into smooth muscle cells, and into cardiomyoblasts expressing Hopx [48]. $\mathrm{Hopx}^{+}$cells give only rise to cardiac myocytes (immature and mature cardiomyocytes).

The participation of the endogenous CPCs to heart regeneration in physiological conditions is controversial [8, 12]. Under pathological conditions, it is now well established that CPCs can differentiate into cardiomyocytes when they were activated with different stimuli, such as FGF-2, thymosin $\beta 4$, prostaglandin $\mathrm{E} 2$, human stem cell factor, or also stromal-cell derived factor 1 (SDF1) [8, 49-53]. However, such involvement seems to be limited in time, as indicated by Hsueh and coworkers who reported that CPC differentiation into cardiomyocytes started at day 7 after MI but saturated on day 10 [51]. Interestingly, in senescent heart, CPCs are quiescent because of lack of stimulation but they can be re-activated by stem cell factor [39]. This suggests that, even in old hearts, activation of endogenous CPCs could be used as a therapeutical way to increase cardiac regeneration.

Among the "direct" activation of CPCs with several factors, the microenvironment of the CPCs can also be modified to increase their potency to participate into heart regeneration. Thus, their migration capacity which is dependent on the SDF1 secreted by the damaged myocardium and its CXCR 4 receptor (expressed by CPCs) can be modulated [54]. The group of Wang induced overexpression of SDF1 by the cardiomyocytes, which led to increased mobilization of 
CPCs [55]. SDF1 has also been shown to activate the endogenous cardioblasts in adult hearts after myocardial infarction [53].

2.3. Role of Infiltrating Cells from Extracardiac Origin. Although the role of infiltrating cells is not yet well defined, inhibition of certain aspects of inflammation is detrimental to cardiac repair after myocardial infarction [56-58], pointing to some role of infiltrating cells in the regenerative process. In this respect, evidence has accumulated that monocytes/macrophages are key players in this scenario [57], a concept notably supported by the increased mortality of MI in mice following transient macrophage depletion [58]. Two different subsets of monocytes originating from the bone marrow, with different, yet complementary functions, are mobilized in the heart after MI: the CD11 $\mathrm{b}^{\text {high }} /$ Ly6 $\mathrm{C}^{\text {high }}$ subset infiltrates the heart 1-3 days after MI, exhibits phagocytic, proteolytic, and inflammatory functions, and represents $75 \%$ of the monocytes in the infarcted hearts at this stage (of note, Ly6 $C^{\text {high }}$ monocytes originating from the spleen have also be

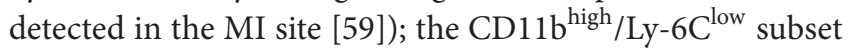
colonizes the heart from day 4 to day 7 and produces less inflammatory mediators but expresses vascular-endothelial growth factor (VEGF), thus promoting angiogenesis [56].

Thus whether a paracrine effect of these cells is now evident (for review see [60]), their ability to differentiate into mature cardiomyocytes remains controversial. Indeed, the differentiation into cardiomyocytes of cells isolated from the bone marrow (BMCs) or the blood was first demonstrated [61-65] and then challenged, with the suggestion that these cells might rather fuse with the native cells instead of differentiating $[64,66,67]$. Finally, now several reports demonstrated that both processes, actual differentiation and fusion, coexist $[68,69]$. This was, for example, demonstrated for human circulating $\mathrm{CD}^{+} 4^{+}$monocytes infiltrating the infarcted myocardium [70] and recently for hematopoietic cells which are able to "fuse" with cardiomyocytes and/or "transdifferentiate" into cardiomyocytes. Whatever the fate of the circulating cells in the heart, numerous factors secreted by these cells have been identified, such as vascular endothelial growth factor (VEGF), insulin growth factor (IGF-1), growth hormone $(\mathrm{GH})$, or hepatocyte growth factor (HGF). These factors promote angiogenesis and atherogenesis but can also stimulate endogenous CPC proliferation and differentiation [71].

\section{Therapeutic Issues in Cardiac Regeneration}

3.1. Cardiac Cell Therapies. The idea leading to the development of cellular therapy in damaged heart is to replace the large amount of cardiomyocytes which died after heart injuries. Thus, cellular therapies, consisting in injecting "cardiomyocyte precursor cells" from various sources into the injured hearts, have been evaluated as the first option in this novel therapeutic paradigm.

Three categories of stem cells could be used: embryonic, adult, and induced pluripotent stem cells (iPSCs). It is important to mention here that, due primarily to ethical issues, only one clinical trial performed so far has used cardiac progenitors derived from human embryonic cells (hESCs) [72]. However, the use of these cells is promising as they regenerate nonhuman primate hearts [73]. In the same way, iPSCs [74] were not yet tested in patients. Furthermore, the discussion is open concerning the use of stem cells from umbilical cord stroma [75].

Thus almost all clinical trials were performed with adult stem cells (Figure 2). The choice of the type of adult precursor cells to inject must be based on 3 main criteria. (1) They should be easily isolated from patients ("autologous cells") or from healthy donors ("allogeneic cells"). (2) They should be expandable in large number (>100 millions in the case of bone marrow cells), implying that the cells should be kept in an undifferentiated state in vitro, to allow high proliferative capacity. (3) They should have the ability to differentiate into mature cardiomyocytes.

Two types of cells fulfilling these criteria have been used in clinical trials: cells isolated from the bone marrow, blood, skeletal muscle, or fat, referred to as "exogenous" precursor cells, and cells isolated from the heart itself (from atrial biopsies) referred to as "endogenous" precursor cells.

3.1.1. The "Exogenous" Precursor Cells. The easiest precursor cells to isolate are obtained from the blood or the bone marrow (BMCs). Thus, a vast majority of clinical trials performed so far used BMCs, either unselected, or sorted according to some markers of undifferentiated BMCs $\left(\mathrm{CD}_{133}{ }^{+}\right.$or $\mathrm{CD} 34^{+}$ enriched BMCs). Mesenchymal stem cells (MSCs), obtained by specific culture processing of the BMCs, have been frequently used as well and indeed are generally presented as the "most effective cells" which can be injected [76].

The results obtained using BMC injection (usually via an intracoronary or a percutaneous transendocardial injection) have been generally disappointing, as summarized in recent extensive reviews [76, 77]. A meta-analysis of 13 randomized trials of unsorted BMC injection in patients with acute MI concluded that BMCs did not prevent the remodeling process [78]. The REPAIR-AMI trial, which is a multicenter doubleblind trial of the intracoronary injection of BMCs after acute MI, reported a $5.5 \%$ increase of left ventricular ejection fraction in post-MI patients at 6 months [79]. However, 18 months after cell injection, no significant difference in left ventricular ejection fraction was detected between cell and placebo injected patients included in the REPAIRAMI trial. Similarly, BMC injection in patients after STelevation myocardial infarction (BOOST trial) led to $6 \%$ increase of the left ventricular ejection fraction 6 months after cell injection $(P=0.003)$ but only to $2.8 \%$ at 18 months $(P=0.27)$ [80]. Recently a meta-analysis using the individual data of the patients involved in 12 randomized trials concluded that intracoronary injection of bone marrow cells after MI provides no benefit for the patients [81].

However, with respect to $\mathrm{CD}_{13}{ }^{+}$enriched BMCs and MSCs, their administration after acute MI did result in moderate improvements of cardiac parameters when compared to control patients with in some cases a small reduction of the absolute scar size [82-84]. Furthermore, patients injected 


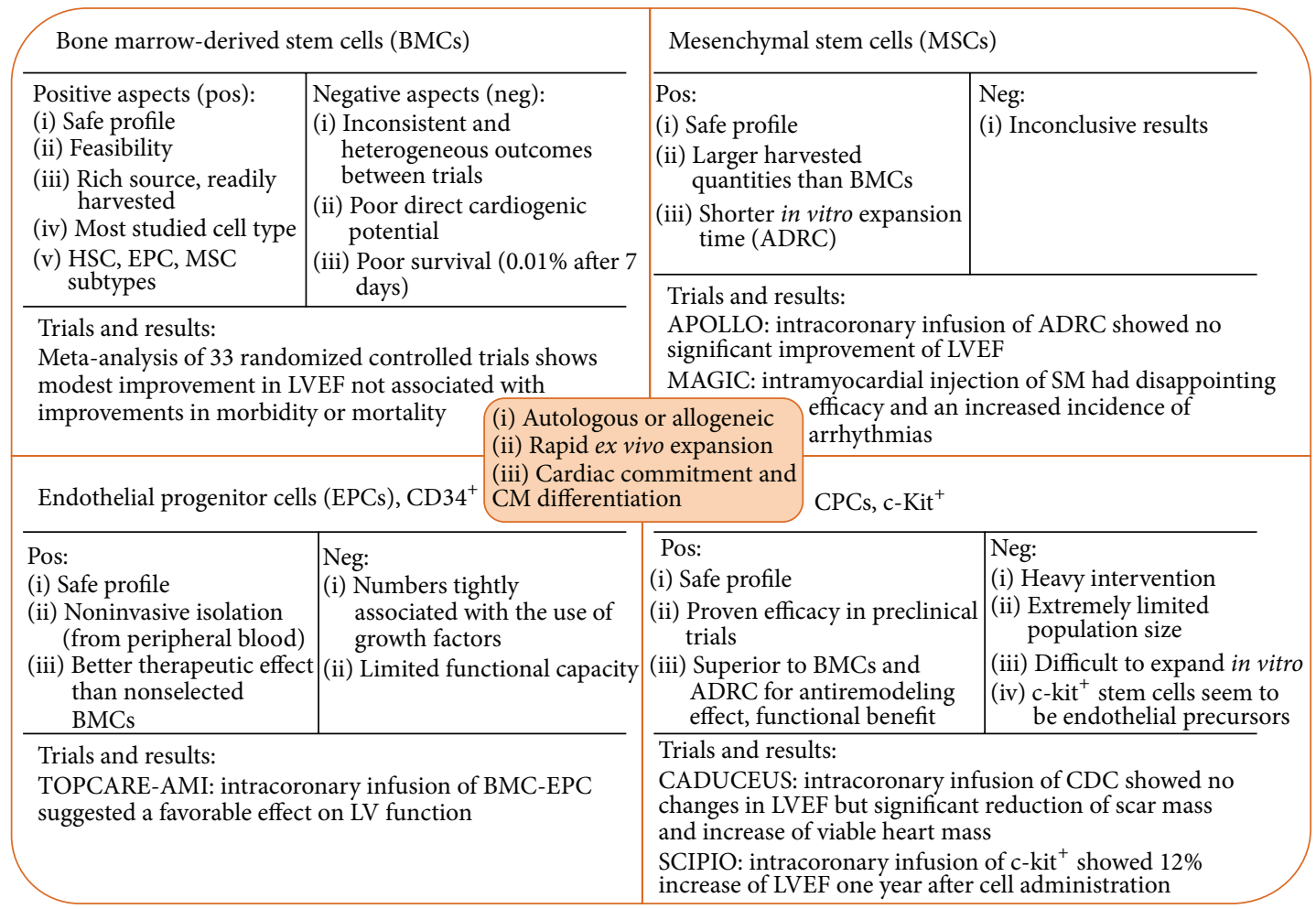

Figure 2: Current state of stem cell therapy for acute myocardial infarction in clinical trials. The optimal cell population for cardiac regenerative cell therapies requires autologous or allogeneic origin, rapid ex vivo expansion, and cardiac commitment including differentiation to cardiomyocytes. Numerous clinical trials have been undertaken with moderate results (for reviews see [8, 77, 172-174]). ADRC: adiposederived stem cells; BMC: bone marrow cells; CDC: cardiosphere-derived cells; CM: cardiomyocytes; EPC: endothelial progenitor cells; HSC: hematopoietic stem cells; LVEF: left ventricular ejection fraction; MSC: mesenchymal stem cells; SC: stem cells.

with a larger percentage of $\mathrm{CD}^{+} 1^{+}$cells among their BMCs, demonstrated a greater reduction of infarct size than patients injected with smaller percentage of $\mathrm{CD}^{+} 1^{+}$[85]. This clearly demonstrates that the nature of the cells which are injected is crucial for the outcome of the therapy.

Cells other than BMCs have been used in some clinical trials. In the MAGIC trial, patients undergoing coronary bypass surgery for previous MI and severe left ventricular dysfunction were injected with skeletal myoblasts (cultured from a muscle biopsy) within the myocardial scar. Myoblast transfer did not improve LV function in comparison to control patients and was associated with early postoperative arrhythmias [86]. Finally, two recent clinical studies used adipose tissue-derived regenerative cells (ADRCs, isolated from liposuction aspirates), administered to patients with acute MI [87] or severe chronic ischemic cardiomyopathy [88]. Results of these studies are encouraging, as ADRCs were associated with a 50\% reduction of myocardial scar formation post-MI and a preserved ventricular function in patients with ischemic cardiomyopathy. Additional studies are needed to confirm these preliminary results.

3.1.2. The "Endogenous" Precursor Cells. Precursor cells do exist within the heart, but their identification has been made difficult by the lack of a highly specific marker. Cells expressing the c-kit have been isolated from the heart, induced to proliferate in vitro and reinjected into patients as cardiac precursor cells from "autologous cardiac origin." The first clinical trials with autologous CPCs used c-kit ${ }^{+}$ cells obtained from atrial biopsies (SCIPIO study) or from cardiospheres (self-assembling multicellular clusters containing various progenitor cells) obtained from right ventricular tissue (CADUCEUS study). The cells have been injected into the coronary circulation of a small number of patients with ischemic cardiomyopathy or acute MI [89, 90]. These trials first indicated the safety of the CPCs administration procedure. Initial results, obtained 6 months after injection, reported a reduction in the myocardial scar mass, although an improvement in cardiac function was only reported in the SCIPIO trial (but concerns regarding scientific integrity of the latter study have been recently raised [91]). At 1-year followup, the CADUCEUS study confirmed the early findings, showing decreased scar size, increased viable myocardium, and improved regional function of the infarcted myocardium [92].

3.1.3. Autologous or Allogeneic Cells? The use of "autologous" injected cells (i.e., cells isolated from the patient itself and reinjected) was first recommended to avoid the immunological problems of rejection. However, their use is limited by the 
fact that they are not immediately available in high number and that their isolation could be difficult in critically affected patients. Furthermore, their immunogenicity is higher than expected. Indeed, their isolation and reinjection, their longterm culture in several culture media (for the mesenchymal stem cells isolated from the bone marrow, see review [93]), and their genetic modification or their epigenetic reprogramming (for the iPSCs see $[94,95]$ ) can increase the expression on their cell surfaces of the major histocompatibility complex (MHC in animals or HLA in humans) classes I or II antigens. These "autologous" cells could be thus rejected after their reinjection and this could explain why in human hearts the long-term survival of injected BMCs is very low: only $2-5 \%$ of the injected autologous BMCs are still present in the heart a few hours after administration [96], and among these surviving cells, only a few actually become correctly integrated cardiomyocytes. Thus, the amount of injected cells which will eventually integrate into the tissue is not sufficient to improve cardiac function. These results highlight the "paracrine" activity of the injected cells which clearly stimulates the "endogenous" cardiac cells, promotes their proliferation and differentiation, or stimulates other repair mechanisms, such as angiogenesis [97, 98].

Thus, if the injected cells can survive long enough to secrete factors able to stimulate the "endogenous" capacity of the heart to regenerate, allogeneic cell therapy can also be considered as a valid option to induce cardiac regeneration. Therefore, injection of allogeneic MSCs in infarcted rat hearts $[99,100]$, dog hearts [101], or pig hearts [102] is safe and improves heart function as well as injection of "autologous" MSCs. Interestingly, human cardioblasts originating from the differentiation of allogeneic MSCs were transplanted into a patient developing a cardiomyopathy and demonstrated positive therapeutical effect for more than 2 years [103]. This is also true for cardiosphere-derived cells (CDCs). Indeed, the efficiency of "allogeneic" CDC injection in patients after myocardial infarction is being evaluated in the ALLSTAR trial and will be compared to this obtained by injection of "autologous" CDCs (evaluated in the CADUCEUS trial [90, 104]). Preclinical results obtained in rats and pigs suggested that injection of allogeneic CDCs was safe, induced no immunological reaction, and acted via the same mechanisms than the autologous CDC injection [105].

The injection of allogeneic cells presents several advantages: these cells could be isolated from "healthy" donors, stocked in "biobanks" in large number, thus immediately available in high numbers for patients. However, the immunogenicity of these cells remains a major hurdle to their use in regenerative medicine. Indeed, if the human precursor cells (especially the MSCs) and the human embryonic stem cells express constitutively the HLA proteins at low levels, when stimulated with interferon gamma or fibroblast growth factor 2 (FGF-2), both cell types increased HLA protein expressions, which render these cells able to be rejected rapidly on transplantation [106-110]. That is why currently many researches are aimed at understanding how blunting host immune responses to injected cells. This concerns the development of strategies limiting, for example, the host immune response (by immunosuppressive drugs, by tolerogenic cell therapies, or also by injection of monoclonal antibodies neutralizing the host immune cells). The immunogenicity of the injected cells can also be modified by modulating the site of injection or the way of cell delivering (some biomaterials can escape from host immune reactivity) (for review see $[111,112]$ ).

3.1.4. Important Conclusions Drawn from Cellular Therapies. To sum up, clinical trials evaluating cellular therapies based on "cardiomyocyte precursor cells" from various sources have not been as successful as expected to repair the injured heart. As a matter of fact, all stem cells used in cell therapies, such as BMCs, mesenchymal or adipose tissue-derived stem cells, display important cytokine secretion. This "paracrine" activity of the injected cells seems to be responsible for the positive effects observed in injured hearts after cell injections. Indeed, secreted factors stimulate the "endogenous" cardiac cells and thus promote their proliferation, differentiation, or other repair mechanisms, such as angiogenesis [97, 98]. Thus, the differentiation of the injected cells into functional cardiomyocytes integrated to the injured hearts seems to contribute only minimally to heart regeneration.

Improving the yield of incorporation/differentiation of injected cells and stimulating growth of endogenous cardiac cells to promote heart regeneration open the way to a new therapeutic paradigm based on a pharmacological standpoint. The fact that spontaneous differentiation (although at very low rate) of endogenous CPCs occurs during life demonstrates that these cells are functional but need to be stimulated $[6,7]$. Future regenerative therapies should therefore capitalize on this feature and propose novel pharmacological strategies to stimulate the proliferation and differentiation of endogenous precursor cells.

\subsection{Pharmacological Therapies to Promote Cell Regeneration}

\subsubsection{The Complex Micorenvironment of Niches Containing} CPCs. CPCs have been shown to be more abundant in the atria, in the heart's apex, and in the epicardium $[113,114]$, where they are located within specialized microdomains termed niches. The niches also contain differentiated cells, such as cardiomyocytes, fibroblasts, or telocytes, which control the activation state of the CPCs via physical interactions (through cell surface receptor and adhesion molecules such as Notch-1 and integrins) or via chemical, paracrine activity (such as the secretion of cytokines and growth factors) [115].

Whereas at the resting state, CPCs in the niches are kept undifferentiated and quiescent, they become activated to proliferate and differentiate into vascular cells or cardiomyocytes following myocardial injury, especially myocardial infarction. In such conditions, the hypoxic microenvironment, as well as molecules released by dying cardiomyocytes, for example, HMGB-1, plays key roles in the activation of CPCs [39, $116,117]$. Furthermore, growing evidence also indicates that infiltrating inflammatory cells recruited within the infarcted hearts promote CPC activation within the niches by releasing 
a wealth of factors, including growth factors (e.g., FGF-2, VEGF), prostaglandins, and cytokines (e.g., IL-10) [49, 51, 71, $76,118]$ (see also Section 2.3).

\subsubsection{Paracrine Activation of CPCs after Myocardial Infarc-} tion: A Role for the Brain Natriuretic Peptide? Thus, it appears evident for us that the identification of a factor able to increase the proliferation and differentiation of the "endogenous" cardiac precursor cells could be a key point in the development of cellular therapies aimed to regenerate injured hearts. That is why we are interested in the brain natriuretic peptide (BNP).

BNP is a cardiac hormone which belongs to the natriuretic peptide family, the other members of which include the atrial natriuretic peptide (ANP) secreted by the cardiac atria and the C-type related natriuretic peptide (CNP) secreted by the brain, bone, and vascular endothelial cells. BNP was first discovered in the bovine brain but it is now well established that the main source of BNP in the body is the heart, especially the ventricles [119]. BNP binds to two distinct guanylyl cyclase receptors, denoted NPR-A and NPR$\mathrm{B}$, promoting the intracellular generation of cyclic GMP (cGMP) [120]. The accumulation of cGMP in the cytoplasm activates protein kinase $\mathrm{G}(\mathrm{PKG})$ and the phosphodiesterases 2,3 , and 5 to elicit downstream signaling [120].

3.2.3. BNP Biosynthesis and Secretion. BNP is a polypeptide of 32 amino acids (32 aa) in humans and pigs and 45 aa in mice and rats. It is processed from a preprohormone of 132aa, posttranslationally modified into a 108-aa prohormone termed proBNP. The latter is enzymatically cleaved by two convertases, namely, corin and/or furin, resulting in an inactive 76-residue amino-terminal fragment (NT-proBNP) and an active 32-aa C-terminal fragment (BNP). Plasma BNP and NT-proBNP can be detected in healthy people, as well as uncleaved proBNP and O-glycosylated proBNP, which are both biologically inactive [121]. Plasma BNP levels increase in patients with various forms of heart failure and are therefore used as a helpful clinical biomarker for the diagnosis and follow-up of cardiac dysfunction [122]. It is here important to mention that recent studies indicated that plasma BNP measured during chronic heart failure rather consists of the biologically inactive forms proBNP and Oglycosylated proBNP $[121,123,124]$. These results have raised the interesting question that heart failure might be in fact associated with a deficit of biologically active BNP [124].

BNP is primarily secreted by ventricular cardiomyocytes upon excessive stretch, increased transmural pressure, or direct injury (see also Figure 3(b) in neonatal hearts). Cardiac fibroblasts and endothelial cells can also secrete BNP, and, following MI, infiltrating immune cells (including neutrophils, $\mathrm{T}$ cells, and macrophages) may represent an additional source of BNP [125]. Interestingly, immature cells such as embryonic stem cells or also satellite cells are also able to secrete BNP $[126,127]$.

3.2.4. Role of BNP in the Heart. Whereas the effects of $\mathrm{BNP}$ on the regulation of natriuresis, diuresis, and vascular tone are well documented, there remains an important gap of knowledge regarding the proper actions of BNP on the heart itself $[119,128]$. In the adult, the rapid release of BNP by the heart might represent an important compensatory protective mechanism in various cardiac pathologies. In support of this assumption, it has been reported that treatment with exogenous BNP facilitated the recovery of cardiac function and improved preservation of cardiac tissue in animal models of MI. Possible mechanisms included the inhibition of cardiomyocyte apoptosis, as well as reduction of hypertrophy and fibrosis [129-134]. BNP may also modulate the immune response to cardiac injury and thereby serve to avert excessive or deregulated inflammation in this setting. Several studies performed in vitro indicated that BNP can inhibit monocyte chemotaxis [135], deplete the number of monocytes, B lymphocytes, and NK cells in cultured human peripheral blood mononuclear cells [136], and regulate the production of a wealth of inflammatory molecules by human macrophages $[137,138]$. In vivo, a study using transgenic mice overexpressing BNP reported increased cardiac neutrophil infiltration and MMP-9 expression after MI in transgenic animals, pointing to a key role of BNP in the processes of matrix remodeling and wound healing in this setting [138].

Several studies also pointed out a role of BNP in cardiac embryogenesis. High levels of BNP are measured during midgestation in embryonic hearts, and peaks of BNP secretion correlate with several important steps of cardiac development $[139,140]$. In addition, recent findings have indicated that cardiomyocyte proliferation can be modulated during development by ANP or BNP [141]. Furthermore, it is noticeable that plasma BNP in humans is high at birth, progressively declining thereafter, to stabilize at around ten years of age to the levels found in adults [142, 143]. Taken together, these observations suggest that BNP may play important functions as a regulator of cardiomyocyte differentiation and proliferation in the developing embryo. In line with this hypothesis, it has been reported that embryonic stem cells express high levels of BNP which are essential for their proliferation and differentiation [126].

These results raise the possibility that BNP might also be involved in the process of cellular regeneration in the adult. A role of BNP was indeed reported by Kuhn et al. in the process of angiogenesis following skeletal muscle ischemia [127]. In this study, secretion of BNP by vascular satellite cells was found to activate, in a paracrine manner, the regeneration of the adjacent endothelium. So, what about cardiac regeneration?

3.2.5. Role of BNP in Cardiac Regeneration. We addressed the role of BNP in cardiac regeneration in our laboratory by performing a series of experiments evaluating the relationships between $\mathrm{CPCs}$ and $\mathrm{BNP}$ both in vitro and in vivo. The first clue for an involvement of BNP in CPC proliferation and differentiation comes from our data indicating the agedependence of BNP expression in the heart. As shown in Figure 3(a) and already published [117], more cardiac cells stained positive for BNP in mouse neonatal compared to adult hearts: in the neonatal hearts $65 \pm 4 \%$ of the cardiac cells were positive for the BNP's staining compared to the adult hearts (41 $\pm 1 \%$ of the cells) (Figure $3(\mathrm{a})$ ). BNP staining is 

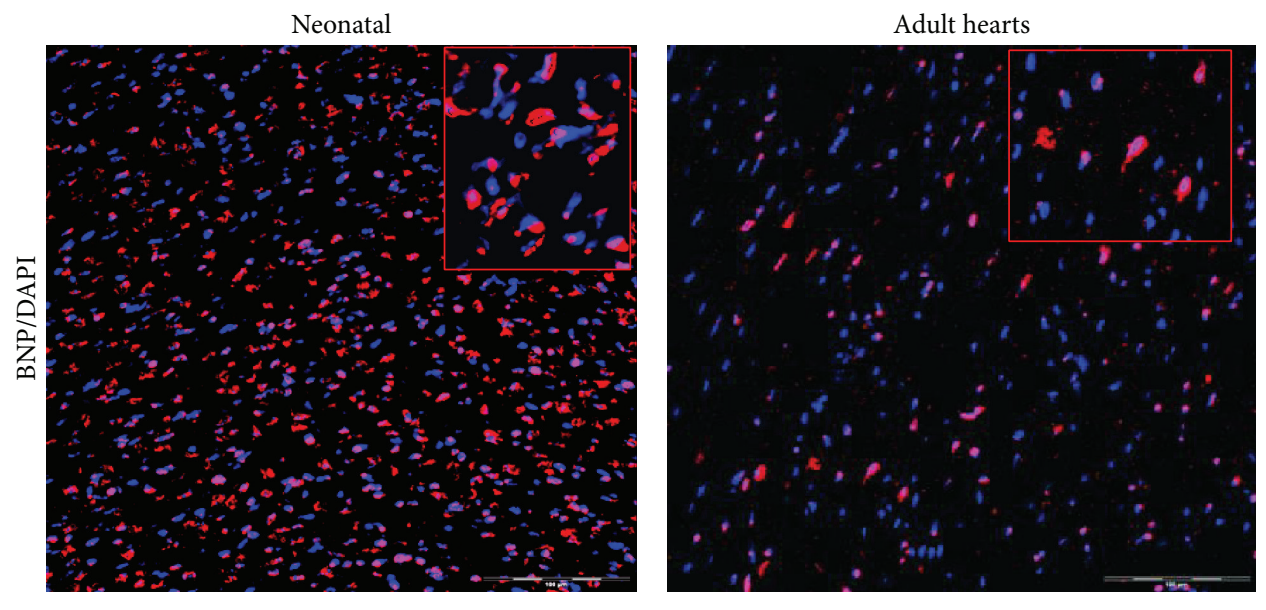

DAPI

BNP

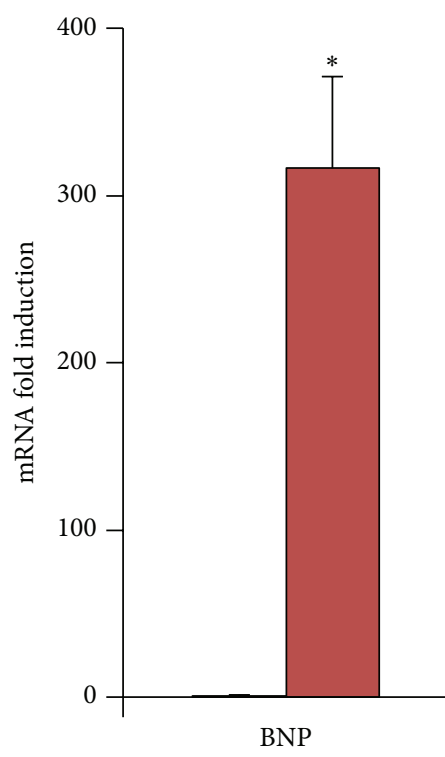

Non-myocyte cells

$\square$ Cardiomyocytes (a)
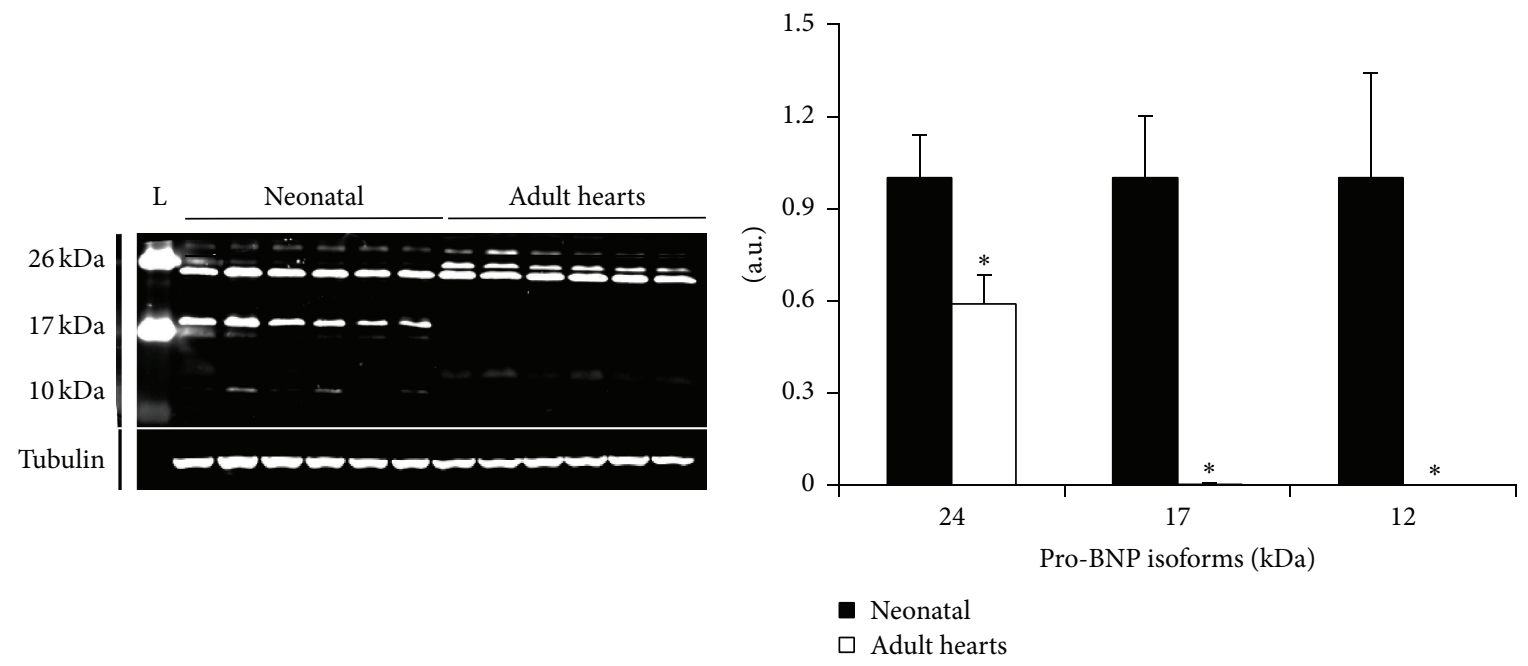

(b)

(c)

FIgURE 3: Heart expression of BNP is age-dependent and cell specific. (a) Representative microscopy pictures of neonatal and adult hearts stained for BNP (in red) and DAPI (nuclei in blue). High magnification of positive cells in top right inserts. The scale bars represent $100 \mu \mathrm{m}$. (b) mRNA expression of BNP using quantitative PCR, in non-myocyte cells (NMCs) (blue) and cardiomyocytes (red). Results expressed as fold-increase above the levels in NMCs. $n=7$ cardiomyocyte samples compared to 9 NMC samples. Data are means \pm SEM, ${ }^{*} P<0.05$. (c) Determination of BNP protein levels in neonatal and adult hearts by western blot analysis. BNP protein expression with representative western blot and quantification relative to tubulin, expressed as fold changes relative to the average level of neonatal hearts. Data are means \pm SEM, ${ }^{*} P<0.05$. a.u.: arbitrary unit.

localized around the nucleus in neonatal and adult cardiac cells (inserts Figure 3(a)). By western blot analysis, several isoforms were detected as our antibody is able to recognize all proBNP isoforms as well as the active form of the BNP (C-terminal peptide). The high molecular weight forms (24 and $17 \mathrm{kDa}$ ) correspond to the glycosylated proBNP isoform (Figure 3(c)) as previously described [144, 145], whereas the proBNP $(12-13 \mathrm{kDa})$ was only detected in the neonatal hearts. According to previous reports, the active BNP form (10 kDa) is not detectable in neonatal or adult hearts by western blot analysis [121, 144]. All proBNP isoforms were more abundant in neonatal than in adult hearts (see quantification in Figure 3(c)).

In the neonatal hearts, BNP mRNA is 300 -fold more abundant in the cardiomyocytes than in the non-myocyte cells (NMCs), suggesting that the mean source of BNP in the neonatal hearts is the cardiomyocytes (Figure 3(b)). This is also true in the adult hearts: BNP mRNA expressed by the 
NMCs represented less than $0.05 \%$ of the mRNA coding for BNP detected in the adult hearts (data not shown).

Further indications for a role of BNP in cardiac growth and/or regeneration come from our finding that CPCs identified in vivo in neonatal and adult hearts express the BNP receptors, NPR-A, and/or NPR-B [117]. Although BNP can share these receptors with other members of the natriuretic peptide family (NPR-A can also bind the atrial natriuretic peptide and NPR-B the C-type related natriuretic peptide) [120], these data strongly support that CPCs are able to respond to BNP. We then found that treatment with exogenous BNP increased the number of newly formed cardiomyocytes and of proliferating CPCs in neonatal and adult unmanipulated mice. Our next finding was that BNP injection in mice exposed to MI resulted in an increased number of CPCs and of cardiomyocytes expressing $\mathrm{Nkx} 2.5$, and this was associated with reduced cardiac remodeling and improved contractile function after MI [117]. Overall, our findings provided strong evidence in support of a crucial role for BNP in controlling proliferation and differentiation of CPCs after birth, therefore suggesting that the administration of BNP might be a useful therapeutic approach to promoting regeneration of the infarcted heart [117].

Furthermore, we observed also that CPCs (identified as being small laminin positive cells expressing $\mathrm{Nkx} 2.5$ $\left(\mathrm{Nkx} 2.5^{+}\right.$cells) or $\mathrm{Sca}-1^{+} / \mathrm{Nkx} 2.5^{+}$cells or $\mathrm{c}-\mathrm{kit}^{+} / \mathrm{Nkx} 2.5^{+}$ cells) stained also positive for BNP, suggesting that CPCs are also able to synthesize BNP (Figure 4). CPCs could thus secrete BNP in an autocrine manner to control their proliferation and differentiation into cardiomyocytes.

3.2.6. Mechanisms of BNP Actions in the Heart: Studies in NPR-A KO and NPR-B Deficient Mice. The demonstration that BNP has potent effects on CPCs prompted us to search for the cellular BNP receptor implicated in such actions. It is known that BNP can bind to two receptors, namely, NPR-A and NPR-B, and we therefore undertook a series of experiments using mice deficient for one or the other of these receptors [120]. We first noticed that the percentage of NPR-A KO mice at birth was lower than expected from the Mendelian frequency (19\% instead of 25\%), suggesting that NPR-A KO embryos die during embryogenesis, as already reported by others [146]. Furthermore, a high rate of mortality occurs in NPR-A KO pups between day 1 and day 10 (at day 10 , only $8 \%$ of the surviving pups are NPR-A KO mice, instead of the expected 25\%, Figure 5). In contrast, NPR-B-deficient pups are born at the expected Mendelian frequency but die within 3 days after birth (Figure 5). These observations implicate BNP receptors in biological processes critical to survival during embryogenesis and early after natal life. This assumption would be consistent with previously reported roles of BNP and BNP receptors in embryonic stem (ES) cells, as reported by Abdelalim and Tooyama [126, 147]. These authors proposed that NPR-A contributed to the self-renewal and maintenance of pluripotency of ES cells, whereas NPR-B was instead involved in their proliferation $[126,147]$.
Cardiac defects could be the cause of the premature death of NPR-A KO pups. Indeed, at 15.5 days of gestation, NPR-A KO embryos display a cardiomegaly without fibrosis, as well as dysregulated expression of the $\mathrm{Cx} 43$ protein, which could affect cardiac contractility [146]. At adulthood, NPR-A KO mice develop salt-resistant hypertension together with cardiac hypertrophy, which is out of proportion with respect to the increase in blood pressure, implying direct antihypertrophic actions of NPR-A in the heart [146, 148150]. Concerning the NPR-B system, previous reports indicated impaired endochondral ossification, gastrointestinal tract disorders, and defects of the reproductive organs in NPR-B-deficient mice [151-155], but there is no result on their cardiac phenotype. Some information has been obtained by the use of transgenic rats expressing a dominantnegative mutant of NPR-B, which display a progressive, blood pressure-independent cardiac hypertrophy, which is further enhanced following the induction of congestive heart failure by volume overload [156]. Therefore, these results support that NPR-B is also involved in the control of cardiac growth.

In our own studies, we recently demonstrated that both receptors control the fate of the cardiac precursor cells in vitro [117]. First, we demonstrated that CPCs exist in neonatal hearts of NPR-A KO and NPR-B-deficient mice. Secondly, we showed that BNP stimulates CPC proliferation in vitro via its binding to NPR-A (Figure 6). Thirdly, we established that BNP stimulates CPC differentiation into cardiomyocytes via binding to NPR-B in cell culture. Whether a defect in the proliferation and/or differentiation of CPCs contributes to cardiac defects and premature death in NPR-A KO and NPR-B-deficient mice remains now to be explored.

3.2.7. The Use of BNP in the Clinic. The first clinical trials with recombinant human BNP (Nesiritide) in patients with acute heart failure reported positive hemodynamic and clinical effects, leading to the common use of this drug in the therapeutic arsenal of both acute and chronic heart failure. Later studies, however, raised several safety concerns about Nesiritide, the drug being possibly associated with greater risk of renal failure and higher mortality, which resulted in significant reduction in its clinical use [157, 158]. Nevertheless, more recent clinical studies reported that low doses of Nesiritide, in particular when administered via subcutaneous route, induced hemodynamic and clinical improvements without increasing nephrotoxicity or the rate of death, thus reopening the debate about the usefulness of BNP therapy in patients with heart failure [157, 159162]. In addition, a recent meta-analysis on the use of natriuretic peptides (ANP/BNP) in patients with acute MI suggested that this treatment might protect left ventricular function [163] and a large-scale randomized clinical trial (BELIEVE II) has been recently initiated to evaluate such cardioprotective effects of low dose BNP during AMI [164].

Finally, it is particularly noteworthy that an inhibitor of neprilysin has been very recently shown to promote significant benefits in patients with chronic heart failure, 

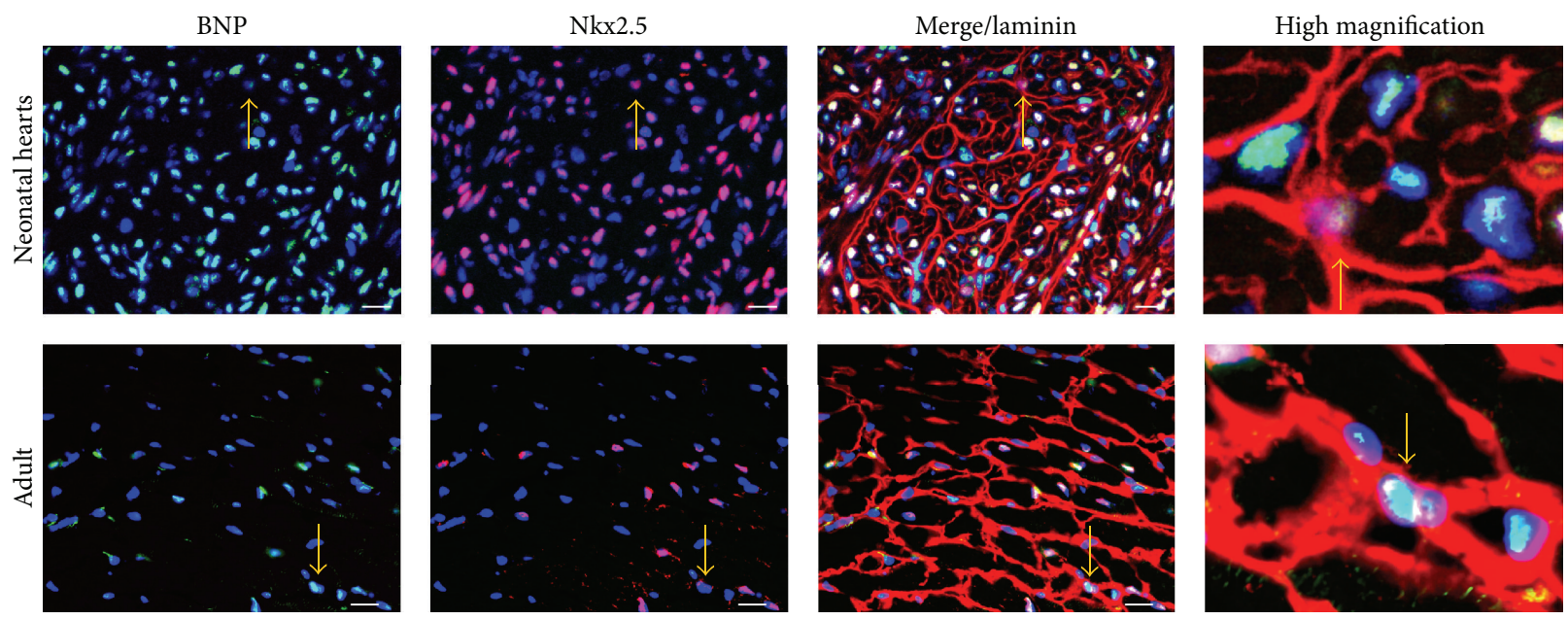

(a)
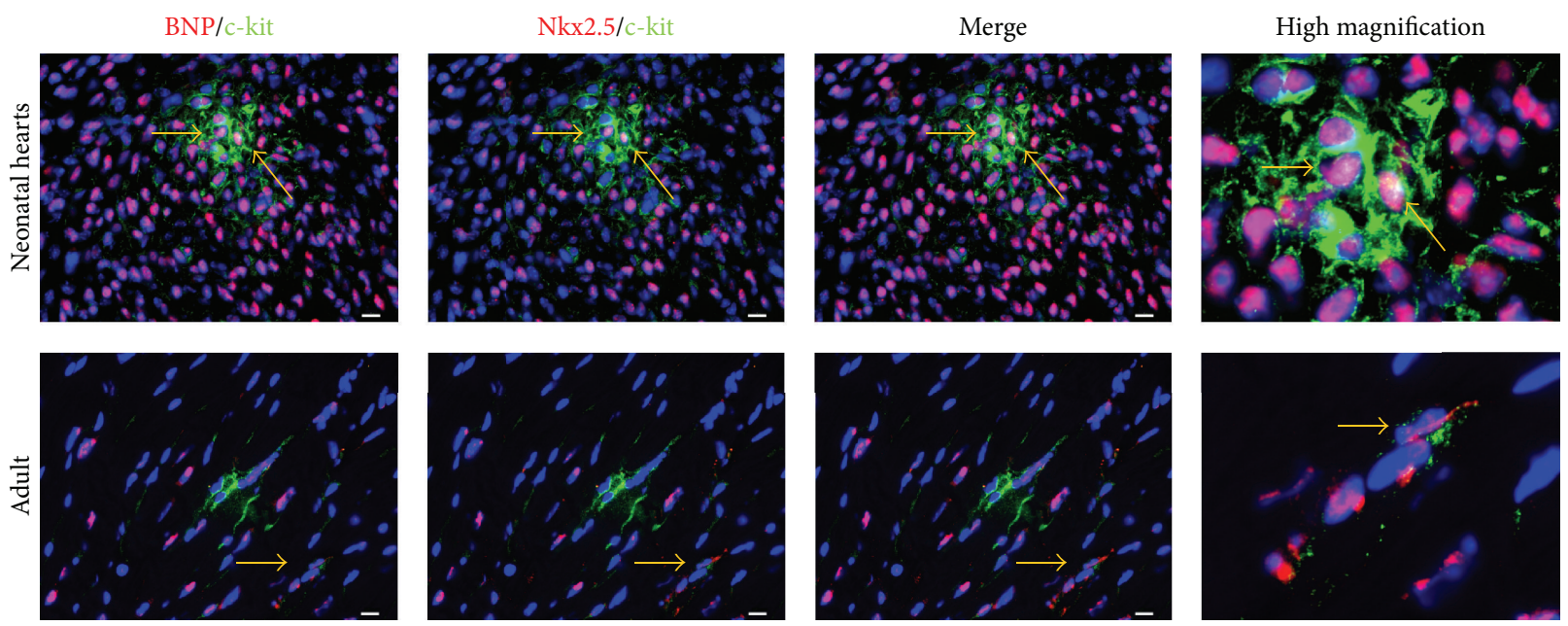

(b)
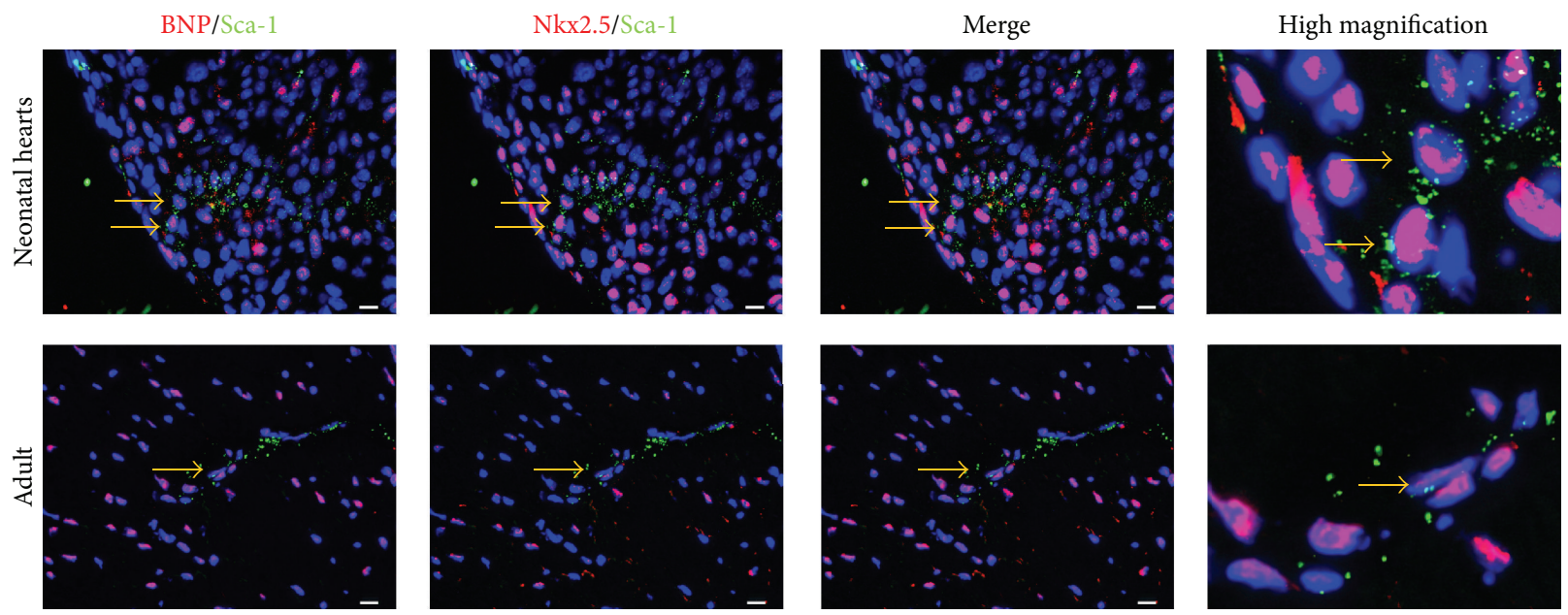

(c)

FIGURE 4: Cardiac precursor cells express BNP in neonatal and adult murine hearts. Cardiac precursor cells were defined as small Nkx2.5 cells or c-kit ${ }^{+} / \mathrm{Nkx} 2.5^{+}$cells or Sca- $1^{+} / \mathrm{Nkx} 2.5^{+}$cells. Photomicrographs of neonatal or adult heart sections stained for BNP and DAPI (Nuclei) associated with staining for either Nkx2.5 and laminin (a), Nkx2.5 and c-kit (b), or Nkx2.5 and Sca-1 (c). Scale bars represent $80 \mu \mathrm{m}$ for the pictures in (a) and $10 \mu \mathrm{m}$ for the pictures in (b) and (c). Yellow arrows depict cells which are considered as being CPCs expressing BNP. 


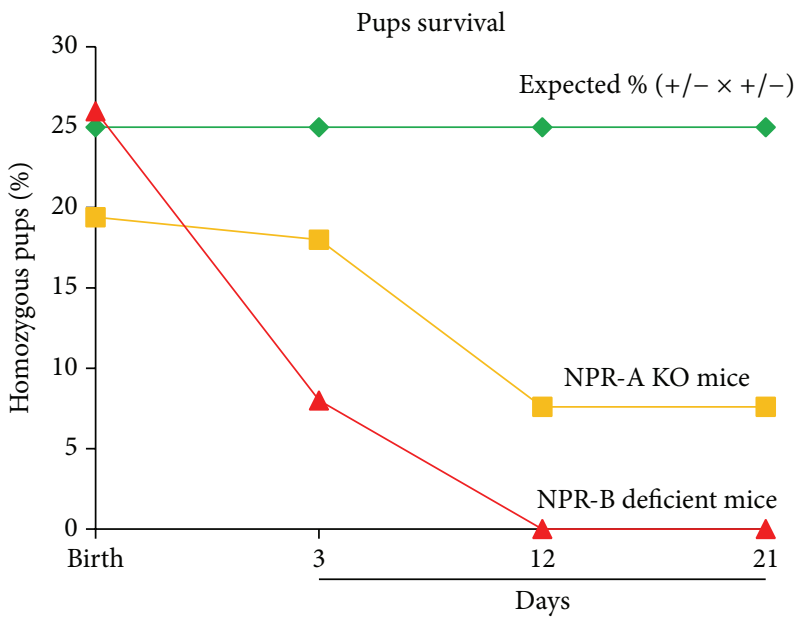

Figure 5: Survival curves of NPR-A KO and NPR-B deficient pups. The results are represented as percentages of the total number of pups ( $n=66$ for NPR-A KO and 96 for NPR-B deficient mice) obtained in heterozygous breeding $(+/-\times+/-$ ) and compared to the expected percentages $(25 \%)$.
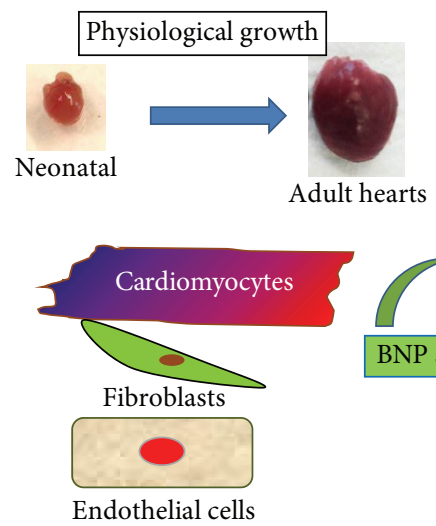

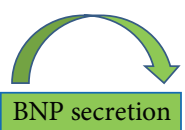

BNP secretion

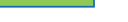

$\theta$
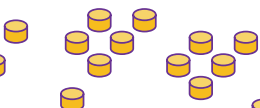
$\Theta$<smiles>C1CCCCCC1</smiles>

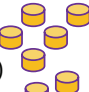
Pathophysiological conditions
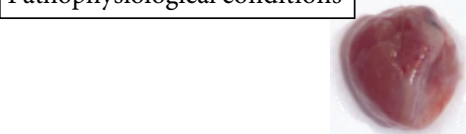

Injured adult hearts

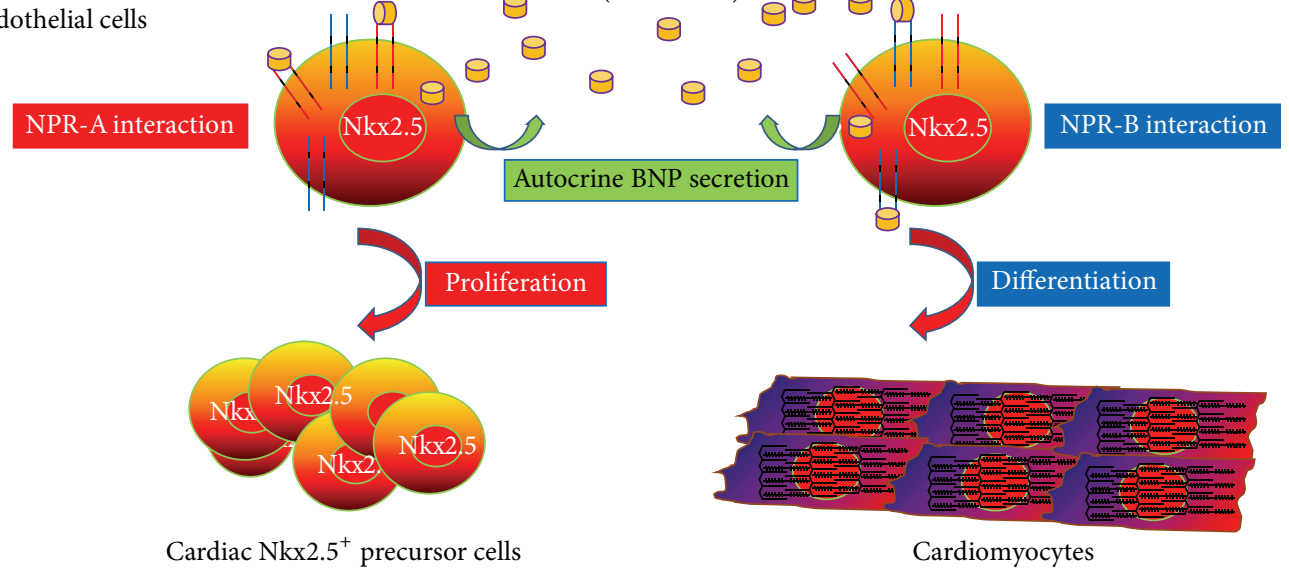

FIGURE 6: BNP modulation of cardiac precursor cell (CPC) proliferation and differentiation. BNP is secreted during physiological growth by cardiomyocytes, fibroblasts, and endothelial cells. CPCs can also secrete BNP. BNP stimulates via NPR-A CPC proliferation and via NPR-B CPC differentiation into cardiomyocytes. In pathophysiological conditions, it seems that the secreted BNP is devoid of biological activity, suggesting that BNP can be injected to stimulate the CPC proliferation and differentiation. This representation is based on the results previously published [117]. 
when compared to angiotensin-converting enzyme inhibition (PARADIGM-HF trial) $[165,166]$. Neprilysin (NEP) is an endopeptidase able to degrade several factors such as the natriuretic peptides (ANP, CNP, and BNP), but also angiotensin II, bradykinin, or endothelin-1. In the heart, NEP is expressed on the membrane of endothelial cells, vascular smooth muscle cells, fibroblasts, and cardiomyocytes and treatments of rats or rabbits with NEP inhibitors increase the blood level of BNP $[167,168]$. However, NEP treatment in animal and humans has also shown to increase the blood level of angiotensin II. That is why NEP inhibitors are used with inhibitors of angiotensin-converting enzyme (ACE) such as the omapatrilat or with blocker of the angiotensin receptor, such as the LCZ696. Omapatrilat has been shown in infarcted mice to increase cardiac function and to decrease the fibrosis and the cardiomyocyte hypertrophy when compared to untreated infarcted mice [169]. However, in humans, omapatrilat was associated with development of angioedema and was not approved by the Food and Drug Administration. Thus great hope focuses now on LCZ696. In infarcted rats, LCZ696 treatment decreases the myocardial fibrosis and the cardiomyocyte hypertrophy and thus increases the ejection fraction of the treated rats compared to untreated one [170].

In patients, the mechanisms of LCZ696 leading to reduced death and rehospitalization are not yet elucidated [171]. However, increasing BNP signaling appears therefore as a meaningful and helpful strategy in patients with myocardial infarction and/or heart failure. Although it is likely that systemic vasodilation and natriuresis are key mechanisms underlying the beneficial effects of natriuretic peptides in the aforementioned studies, the positive effects of BNP on cardiac regenerative processes, as highlighted in our recent work, could also play an important role, an issue which should be critically addressed in ongoing clinical and experimental studies.

\section{Conclusion-Future Perspectives}

Therapy of cardiovascular diseases represents a major public health challenge. Primary prevention, including lifestyle modification and treatment of traditional cardiovascular risk factors, together with secondary and tertiary prevention by multidrug treatment, has been the mainstay of such therapy for decades. In recent years, novel approaches based upon the regeneration of the injured heart have been developed, holding the promise not only to relieve, but also to directly repair the damaged heart. The observation that stem cells isolated from different organs retain the ability to differentiate into mature adult beating cardiomyocytes promoted strong impetus to launch a series of clinical trials evaluating the therapeutic potential of cellular regenerative therapies in cardiac diseases. Lessons learned from these studies indicated that although such approaches appeared generally safe, their efficacy remained globally limited. Factors such as the nature of the injected cells, their number, and the route and timing of their administration emerged as critical issues which will need to be addressed in future studies to improve such efficacy. Furthermore, it has become obvious that cardiac regeneration involves complex interplays between different cell subsets of both cardiac and extracardiac (blood or bone marrow) origin, which cannot be mimicked by the one and only administration of cardiac precursor cells. A potential strategy to circumvent, at least partly, the limitations of cellular regenerative therapies could rely on the stimulation of the heart's natural ability to induce its own regeneration by pharmacological approaches. Indeed, pharmacological compounds could target not only the cellular precursors but also other cells involved in the regenerative and healing process, for instance, the fibroblasts, the endothelial cells, and the infiltrating cells, such as the different monocyte subsets. Treatment with exogenous brain natriuretic peptide is an example of such strategy, as demonstrated experimentally by its ability to induce "endogenous" cardiac regeneration. Future studies should endeavor to discover novel molecules able to stimulate such genuine capacity of the heart to regenerate, which would represent an indisputable breakthrough in the fight against cardiovascular diseases.

\section{Conflict of Interests}

No author has any conflict of interests to disclose with respect to this paper.

\section{Acknowledgments}

This work is supported by a grant from the Swiss National Science Foundation (PMPDB-310030_132491) and by the Swiss Cardiology Foundation.

\section{References}

[1] R. Kelishadi and P. Poursafa, "A review on the genetic, environmental, and lifestyle aspects of the early-life origins of cardiovascular disease," Current Problems in Pediatric and Adolescent Health Care, vol. 44, no. 3, pp. 54-72, 2014.

[2] N. D. Wong, "Epidemiological studies of CHD and the evolution of preventive cardiology," Nature Reviews Cardiology, vol. 11, no. 5, pp. 276-289, 2014.

[3] J. J. V. McMurray, S. Adamopoulos, S. D. Anker et al., "ESC Guidelines for the diagnosis and treatment of acute and chronic heart failure 2012: the Task Force for the Diagnosis and Treatment of Acute and Chronic Heart Failure 2012 of the European Society of Cardiology. Developed in collaboration with the Heart Failure Association (HFA) of the ESC," European heart journal, vol. 33, no. 14, pp. 1787-1847, 2012.

[4] S. Ausoni and S. Sartore, "From fish to amphibians to mammals: in search of novel strategies to optimize cardiac regeneration," Journal of Cell Biology, vol. 184, no. 3, pp. 357-364, 2009.

[5] S. Ausoni and S. Sartore, "The cardiovascular unit as a dynamic player in disease and regeneration," Trends in Molecular Medicine, vol. 15, no. 12, pp. 543-552, 2009.

[6] O. Bergmann, R. D. Bhardwaj, S. Bernard et al., "Evidence for cardiomyocyte renewal in humans," Science, vol. 324, no. 5923, pp. 98-102, 2009.

[7] J. Kajstura, N. Gurusamy, B. Ogórek et al., "Myocyte turnover in the aging human heart," Circulation Research, vol. 107, no. 11, pp. 1374-1386, 2010. 
[8] P. C. H. Hsieh, V. F. M. Segers, M. E. Davis et al., "Evidence from a genetic fate-mapping study that stem cells refresh adult mammalian cardiomyocytes after injury," Nature Medicine, vol. 13, no. 8, pp. 970-974, 2007.

[9] A. Leri, M. Rota, F. S. Pasqualini, P. Goichberg, and P. Anversa, "Origin of cardiomyocytes in the adult heart," Circulation Research, vol. 116, no. 1, pp. 150-166, 2015.

[10] M. A. Laflamme and C. E. Murry, "Heart regeneration," Nature, vol. 473, no. 7347, pp. 326-335, 2011.

[11] E. R. Porrello, A. I. Mahmoud, E. Simpson et al., "Transient regenerative potential of the neonatal mouse heart," Science, vol. 331, no. 6020, pp. 1078-1080, 2011.

[12] S. E. Senyo, M. L. Steinhauser, C. L. Pizzimenti et al., "Mammalian heart renewal by pre-existing cardiomyocytes," Nature, vol. 493, no. 7432, pp. 433-436, 2013.

[13] S. R. Ali, S. Hippenmeyer, L. V. Saadat, L. Luo, I. L. Weissman, and R. Ardehali, "Existing cardiomyocytes generate cardiomyocytes at a low rate after birth in mice," Proceedings of the National Academy of Sciences of the United States of America, vol. 111, no. 24, pp. 8850-8855, 2014.

[14] C. Jopling, E. Sleep, M. Raya, M. Martí, A. Raya, and J. C. Izpisua Belmonte, "Zebrafish heart regeneration occurs by cardiomyocyte dedifferentiation and proliferation," Nature, vol. 464, no. 7288, pp. 606-609, 2010.

[15] Y. Zhang, T.-S. Li, S.-T. Lee et al., "Dedifferentiation and proliferation of mammalian cardiomyocytes," PLOS ONE, vol. 5, no. 9, Article ID e12559, 2010.

[16] G. D. Dispersyn, L. Mesotten, B. Meuris et al., "Dissociation of cardiomyocyte apoptosis and dedifferentiation in infarct border zones," European Heart Journal, vol. 23, no. 11, pp. 849-857, 2002.

[17] R. B. Driesen, F. K. Verheyen, W. Debie et al., "Re-expression of alpha skeletal actin as a marker for dedifferentiation in cardiac pathologies," Journal of Cellular and Molecular Medicine, vol. 13, no. 5, pp. 896-908, 2009.

[18] T. Kubin, J. Pöling, S. Kostin et al., "Oncostatin M is a major mediator of cardiomyocyte dedifferentiation and remodeling," Cell Stem Cell, vol. 9, no. 5, pp. 420-432, 2011.

[19] C. Rücker-Martin, F. Pecker, D. Godreau, and S. N. Hatem, "Dedifferentiation of atrial myocytes during atrial fibrillation: role of fibroblast proliferation in vitro," Cardiovascular Research, vol. 55, no. 1, pp. 38-52, 2002.

[20] J. Pöling, P. Gajawada, H. Lörchner et al., "The Janus face of OSM-mediated cardiomyocyte dedifferentiation during cardiac repair and disease," Cell Cycle, vol. 11, no. 3, pp. 439-445, 2012.

[21] K. Bersell, S. Arab, B. Haring, and B. Kühn, "Neuregulin1/ErbB4 signaling induces cardiomyocyte proliferation and repair of heart injury," Cell, vol. 138, no. 2, pp. 257-270, 2009.

[22] T. Braun and S. Dimmeler, "Breaking the silence: stimulating proliferation of adult cardiomyocytes," Developmental Cell, vol. 17, no. 2, pp. 151-153, 2009.

[23] G. D'Uva, A. Aharonov, M. Lauriola et al., "ERBB2 triggers mammalian heart regeneration by promoting cardiomyocyte dedifferentiation and proliferation," Nature Cell Biology, vol. 17, no. 5, pp. 627-638, 2015.

[24] C. E. Rupert and K. L. Coulombe, "The roles of neuregulin-1 in cardiac development, homeostasis, and disease," Biomarker Insights, vol. 10, pp. 1-9, 2015.

[25] B. Kühn, F. del Monte, R. J. Hajjar et al., "Periostin induces proliferation of differentiated cardiomyocytes and promotes cardiac repair," Nature Medicine, vol. 13, no. 8, pp. 962-969, 2007.
[26] F. R. Formiga, B. Pelacho, E. Garbayo et al., "Controlled delivery of fibroblast growth factor-1 and neuregulin-1 from biodegradable microparticles promotes cardiac repair in a rat myocardial infarction model through activation of endogenous regeneration," Journal of Controlled Release, vol. 173, no. 1, pp. 132-139, 2014.

[27] T. Novoyatleva, A. Sajjad, D. Pogoryelov, C. Patra, R. T. Schermuly, and F. B. Engel, "FGF1-mediated cardiomyocyte cell cycle reentry depends on the interaction of FGFR-1 and Fn14," FASEB Journal, vol. 28, no. 6, pp. 2492-2503, 2014.

[28] C. J. Hou, Y. M. Qi, D. Z. Zhang et al., "The proliferative and migratory effects of physical injury and stromal cell-derived factor- $1 \alpha$ on rat cardiomyocytes and fibroblasts," European Review for Medical and Pharmacological Sciences, vol. 19, no. 7, pp. 1252-1257, 2015.

[29] A. Eulalio, M. Mano, M. Dal Ferro et al., "Functional screening identifies miRNAs inducing cardiac regeneration," Nature, vol. 492, no. 7429, pp. 376-381, 2012.

[30] W. Kimura, F. Xiao, D. C. Canseco et al., "Hypoxia fate mapping identifies cycling cardiomyocytes in the adult heart," Nature, vol. 523, no. 7559, pp. 226-230, 2015.

[31] B. N. Puente, W. Kimura, S. A. Muralidhar et al., "The oxygenrich postnatal environment induces cardiomyocyte cell-cycle arrest through DNA damage response," Cell, vol. 157, no. 3, pp. 565-579, 2014.

[32] H. M. Kaija, T. Särkioja, M.-L. Kortelainen, J. T. Vuoristo, H. V. Huikuri, and K. S. Porvari, "Stress-specific responses of p21 expression: implication of transcript variant p21 alt-a in longterm hypoxia," Journal of Cellular Biochemistry, vol. 113, no. 2, pp. 544-552, 2012.

[33] A. I. Mahmoud, F. Kocabas, S. A. Muralidhar et al., "Meis1 regulates postnatal cardiomyocyte cell cycle arrest," Nature, vol. 497, no. 7448, pp. 249-253, 2013.

[34] D. C. Canseco, W. Kimura, S. Garg et al., "Human ventricular unloading induces cardiomyocyte proliferation," Journal of the American College of Cardiology, vol. 65, no. 9, pp. 892-900, 2015.

[35] K.-L. Laugwitz, A. Moretti, L. Caron, A. Nakano, and K. R. Chien, "Isletl cardiovascular progenitors: a single source for heart lineages?" Development, vol. 135, no. 2, pp. 193-205, 2008.

[36] T. Brade, L. S. Pane, A. Moretti, K. R. Chien, and K.-L. Laugwitz, "Embryonic heart progenitors and cardiogenesis," Cold Spring Harbor Perspectives in Medicine, vol. 3, no. 10, Article ID a013847, 2013.

[37] J. Ferreira-Martins, B. Ogórek, D. Cappetta et al., "Cardiomyogenesis in the developing heart is regulated by c-kit-positive cardiac stem cells," Circulation Research, vol. 110, no. 5, pp. 701$715,2012$.

[38] G. M. Ellison, C. Vicinanza, A. J. Smith et al., "Adult c-kit(pos) cardiac stem cells are necessary and sufficient for functional cardiac regeneration and repair," Cell, vol. 154 , no. 4, pp. $827-$ 842, 2013.

[39] F. Sanada, J. Kim, A. Czarna et al., "c-Kit-positive cardiac stem cells nested in hypoxic niches are activated by stem cell factor reversing the aging myopathy," Circulation Research, vol. 114, no. 1, pp. 41-55, 2014.

[40] S. J. Kattman, T. L. Huber, and G. M. Keller, "Multipotent Flk-1 $1^{+}$ cardiovascular progenitor cells give rise to the cardiomyocyte, endothelial, and vascular smooth muscle lineages," Developmental Cell, vol. 11, no. 5, pp. 723-732, 2006.

[41] V. Di Felice and G. Zummo, "Stem cell populations in the heart and the role of Isll positive cells," European Journal of Histochemistry, vol. 57, article e14, 2013. 
[42] L. Bu, X. Jiang, S. Martin-Puig et al., "Human ISL1 heart progenitors generate diverse multipotent cardiovascular cell lineages," Nature, vol. 460, no. 7251, pp. 113-117, 2009.

[43] K. Hidaka, J.-K. Lee, H. S. Kim et al., "Chamber-specific differentiation of Nkx2.5-positive cardiac precursor cells from murine embryonic stem cells," The FASEB Journal, vol. 17, no. 6 , pp. 740-742, 2003.

[44] A. Armiñán, C. Gandía, M. Bartual et al., "Cardiac differentiation is driven by NKX2.5 and GATA4 nuclear translocation in tissue-specific mesenchymal stem cells," Stem Cells and Development, vol. 18, no. 6, pp. 907-918, 2009.

[45] M. Takamiya, K. H. Haider, and M. Ashraf, "Identification and characterization of a novel multipotent sub-population of Sca$1(+)$ cardiac progenitor cells for myocardial regeneration," PLoS ONE, vol. 6, no. 9, Article ID e25265, 2011.

[46] A. Moretti, M. Bellin, C. B. Jung et al., "Mouse and human induced pluripotent stem cells as a source for multipotent Isl1+ cardiovascular progenitors," The FASEB Journal, vol. 24, no. 3, pp. 700-711, 2010.

[47] T. I. Fuentes, N. Appleby, E. Tsay et al., "Human neonatal cardiovascular progenitors: unlocking the secret to regenerative ability," PLoS ONE, vol. 8, no. 10, Article ID e77464, 2013.

[48] R. Jain, D. Li, M. Gupta et al., "Integration of BMP and WNT signaling by Hopx specifies commitment of cardiomyoblasts," Science, vol. 348, no. 6242, Article ID aaa6071, 2015.

[49] N. Rosenblatt-Velin, M. G. Lepore, C. Cartoni, F. Beermann, and T. Pedrazzini, "FGF-2 controls the differentiation of resident cardiac precursors into functional cardiomyocytes," Journal of Clinical Investigation, vol. 115, no. 7, pp. 1724-1733, 2005.

[50] N. Smart, S. Bollini, K. N. Dubé et al., "De novo cardiomyocytes from within the activated adult heart after injury," Nature, vol. 474, no. 7353, pp. 640-644, 2011.

[51] Y.-C. Hsueh, J. M. F. Wu, C.-K. Yu, K. K. Wu, and P. C. H. Hsieh, "Prostaglandin $\mathrm{E}_{2}$ promotes post-infarction cardiomyocyte replenishment by endogenous stem cells," EMBO Molecular Medicine, vol. 6, no. 4, pp. 496-503, 2014.

[52] F. L. Xiang, Y. Liu, X. Lu, D. L. Jones, and Q. Feng, "Cardiacspecific overexpression of human stem cell factor promotes epicardial activation and arteriogenesis after myocardial infarction," Circulation: Heart Failure, vol. 7, no. 5, pp. 831-842, 2014.

[53] K. Malliaras, A. Ibrahim, E. Tseliou et al., "Stimulation of endogenous cardioblasts by exogenous cell therapy after myocardial infarction," EMBO Molecular Medicine, vol. 6, no. 6, pp. 760-777, 2014.

[54] V. F. M. Segers, T. Tokunou, L. J. Higgins, C. MacGillivray, J. Gannon, and R. T. Lee, "Local delivery of protease-resistant stromal cell derived factor-1 for stem cell recruitment after myocardial infarction," Circulation, vol. 116, no. 15, pp. 16831692, 2007.

[55] K. Wang, X. Zhao, C. Kuang et al., "Overexpression of SDF-1 $\alpha$ enhanced migration and engraftment of cardiac stem cells and reduced infarcted size via CXCR4/PI3K pathway," PLoS ONE, vol. 7, no. 9, Article ID e43922, 2012.

[56] M. Nahrendorf, F. K. Swirski, E. Aikawa et al., "The healing myocardium sequentially mobilizes two monocyte subsets with divergent and complementary functions," The Journal of Experimental Medicine, vol. 204, no. 12, pp. 3037-3047, 2007.

[57] M. P. Santini and N. Rosenthal, "Myocardial regenerative properties of macrophage populations and stem cells," Journal of Cardiovascular Translational Research, vol. 5, no. 5, pp. 700712, 2012.
[58] T. Ben-Mordechai, R. Holbova, N. Landa-Rouben et al., "Macrophage subpopulations are essential for infarct repair with and without stem cell therapy," Journal of the American College of Cardiology, vol. 62, no. 20, pp. 1890-1901, 2013.

[59] F. K. Swirski, M. Nahrendorf, M. Etzrodt et al., "Identification of splenic reservoir monocytes and their deployment to inflammatory sites," Science, vol. 325, no. 5940, pp. 612-616, 2009.

[60] Y. M. Klyachkin, A. V. Karapetyan, M. Z. Ratajczak, and A. Abdel-Latif, "The role of bioactive lipids in stem cell mobilization and homing: novel therapeutics for myocardial ischemia," BioMed Research International, vol. 2014, Article ID 653543, 12 pages, 2014.

[61] J. Kajstura, M. Rota, B. Whang et al., "Bone marrow cells differentiate in cardiac cell lineages after infarction independently of cell fusion," Circulation Research, vol. 96, no. 1, pp. 127-137, 2005.

[62] D. Orlic, "Adult bone marrow stem cells regenerate myocardium in ischemic heart disease," Annals of the New York Academy of Sciences, vol. 996, pp. 152-157, 2003.

[63] C. Badorff, R. P. Brandes, R. Popp et al., "Transdifferentiation of blood-derived human adult endothelial progenitor cells into functionally active cardiomyocytes," Circulation, vol. 107, no. 7, pp. 1024-1032, 2003.

[64] N. Terada, T. Hamazaki, M. Oka et al., "Bone marrow cells adopt the phenotype of other cells by spontaneous cell fusion," Nature, vol. 416, no. 6880, pp. 542-545, 2002.

[65] D. Orlic, J. Kajstura, S. Chimenti et al., "Mobilized bone marrow cells repair the infarcted heart, improving function and survival," Proceedings of the National Academy of Sciences of the United States of America, vol. 98, no. 18, pp. 10344-10349, 2001.

[66] C. E. Murry, M. H. Soonpaa, H. Reinecke et al., "Haematopoietic stem cells do not transdifferentiate into cardiac myocytes in myocardial infarcts," Nature, vol. 428, no. 6983, pp. 664-668, 2004.

[67] J. M. Nygren, S. Jovinge, M. Breitbach et al., "Bone marrowderived hematopoietic cells generate cardiomyocytes at a low frequency through cell fusion, but not transdifferentiation," Nature Medicine, vol. 10, no. 5, pp. 494-501, 2004.

[68] M. Rota, J. Kajstura, T. Hosoda et al., "Bone marrow cells adopt the cardiomyogenic fate in vivo," Proceedings of the National Academy of Sciences of the United States of America, vol. 104, no. 45, pp. 17783-17788, 2007.

[69] J. Yoon, S.-C. Choi, C.-Y. Park et al., "Bone marrow-derived side population cells are capable of functional cardiomyogenic differentiation," Molecules and Cells, vol. 25, no. 2, pp. 216-223, 2008.

[70] H. Kodama, T. Inoue, R. Watanabe et al., "Cardiomyogenic potential of mesenchymal progenitors derived from human circulating CD14 ${ }^{+}$monocytes," Stem Cells and Development, vol. 14, no. 6, pp. 676-686, 2005.

[71] F. S. Loffredo, M. L. Steinhauser, J. Gannon, and R. T. Lee, "Bone marrow-derived cell therapy stimulates endogenous cardiomyocyte progenitors and promotes cardiac repair," Cell Stem Cell, vol. 8, no. 4, pp. 389-398, 2011.

[72] P. Menasché, V. Vanneaux, J. R. Fabreguettes et al., “Towards a clinical use of human embryonic stem cell-derived cardiac progenitors: a translational experience," European Heart Journal, vol. 36, no. 12, pp. 743-750, 2014.

[73] J. J. H. Chong, X. Yang, C. W. Don et al., "Human embryonicstem-cell-derived cardiomyocytes regenerate non-human primate hearts," Nature, vol. 510, no. 7504, pp. 273-277, 2014. 
[74] M. Malecki, E. Putzer, C. Sabo et al., "Directed cardiomyogenesis of autologous human induced pluripotent stem cells recruited to infarcted myocardium with bioengineered antibodies," Molecular and Cellular Therapies, vol. 2, article 13, 2014.

[75] Z. Ding, S. Burghoff, A. Buchheiser, G. Kögler, and J. Schrader, "Survival, integration, and differentiation of unrestricted somatic stem cells in the heart," Cell Transplantation, vol. 22, no. 1, pp. 15-27, 2013.

[76] P. Menasche, "Cardiac cell therapy: lessons from clinical trials," Journal of Molecular and Cellular Cardiology, vol. 50, no. 2, pp. 258-265, 2011.

[77] P. P. Young and R. Schäfer, "Cell-based therapies for cardiac disease: a cellular therapist's perspective," Transfusion, vol. 55, no. 2, pp. 441-451, 2015.

[78] E. Martin-Rendon, S. Brunskill, C. Dorée et al., "Stem cell treatment for acute myocardial infarction," Cochrane Database of Systematic Reviews, vol. 4, Article ID CD006536, 2008.

[79] V. Schächinger, S. Erbs, A. Elsässer et al., "Intracoronary bone marrow-derived progenitor cells in acute myocardial infarction," The New England Journal of Medicine, vol. 355, no. 12, pp. 1210-1221, 2006.

[80] G. P. Meyer, K. C. Wollert, J. Lotz et al., "Intracoronary bone marrow cell transfer after myocardial infarction: 5-year followup from the randomized-controlled BOOST trial," European Heart Journal, vol. 30, no. 24, pp. 2978-2984, 2009.

[81] M. Gyöngyösi, W. Wojakowski, P. Lemarchand et al., "Metaanalysis of cell-based cardiac studies (ACCRUE) in patients with acute myocardial infarction based on individual patient data," Circulation Research, vol. 116, no. 8, pp. 1346-1360, 2015.

[82] S. Golpanian, J. El-Khorazaty, A. Mendizabal et al., "Effect of aging on human mesenchymal stem cell therapy in ischemic cardiomyopathy patients," Journal of the American College of Cardiology, vol. 65, no. 2, pp. 125-132, 2015.

[83] B. A. Nasseri, W. Ebell, M. Dandel et al., "Autologous CD133+ bone marrow cells and bypass grafting for regeneration of ischaemic myocardium: the Cardiol33 trial," European Heart Journal, vol. 35, no. 19, pp. 1263-1274, 2014.

[84] J. M. Hare, J. H. Traverse, T. D. Henry et al., "A randomized, double-blind, placebo-controlled, dose-escalation study of intravenous adult human mesenchymal stem cells (prochymal) after acute myocardial infarction," Journal of the American College of Cardiology, vol. 54, no. 24, pp. 2277-2286, 2009.

[85] R. C. Schutt, B. H. Trachtenberg, J. P. Cooke et al., "Bone marrow characteristics associated with changes in infarct size after STEMI: a biorepository evaluation from the CCTRN TIME trial," Circulation Research, vol. 116, no. 1, pp. 99-107, 2015.

[86] P. Menasché, O. Alfieri, S. Janssens et al., "The myoblast autologous grafting in ischemic cardiomyopathy (MAGIC) trial: first randomized placebo-controlled study of myoblast transplantation," Circulation, vol. 117, no. 9, pp. 1189-1200, 2008.

[87] J. H. Houtgraaf, W. K. den Dekker, B. M. van Dalen et al., "First experience in humans using adipose tissue-derived regenerative cells in the treatment of patients with ST-segment elevation myocardial infarction," Journal of the American College of Cardiology, vol. 59, no. 5, pp. 539-540, 2012.

[88] E. C. Perin, R. Sanz-Ruiz, P. L. Sánchez et al., "Adipose-derived regenerative cells in patients with ischemic cardiomyopathy: the PRECISE Trial," American Heart Journal, vol. 168, no. 1, pp. 8895.e2, 2014.

[89] R. Bolli, A. R. Chugh, D. D’Amario et al., "Cardiac stem cells in patients with ischaemic cardiomyopathy (SCIPIO): initial results of a randomised phase 1 trial," The Lancet, vol. 378, no. 9806, pp. 1847-1857, 2011.

[90] R. R. Makkar, R. R. Smith, K. Cheng et al., "Intracoronary cardiosphere-derived cells for heart regeneration after myocardial infarction (CADUCEUS): a prospective, randomised phase 1 trial," The Lancet, vol. 379, no. 9819, pp. 895-904, 2012.

[91] The Lancet Editors, "Expression of concern: the SCIPIO trial," The Lancet, vol. 383, no. 9925, p. 1279, 2014.

[92] K. Malliaras, R. R. Makkar, R. R. Smith et al., "Intracoronary cardiosphere-derived cells after myocardial infarction: evidence of therapeutic regeneration in the final 1-year results of the CADUCEUS trial (cardiosphere-derived autologous stem cells to reverse ventricular dysfunction)," Journal of the American College of Cardiology, vol. 63, no. 2, pp. 110-122, 2014.

[93] N. Haque, N. H. Abu Kasim, and M. T. Rahman, "Optimization of pre-transplantation conditions to enhance the efficacy of mesenchymal stem cells," International Journal of Biological Sciences, vol. 11, no. 3, pp. 324-334, 2015.

[94] J. M. Polo, S. Liu, M. E. Figueroa et al., "Cell type of origin influences the molecular and functional properties of mouse induced pluripotent stem cells," Nature Biotechnology, vol. 28, no. 8 , pp. $848-855,2010$.

[95] G. Liang and Y. Zhang, "Genetic and epigenetic variations in iPSCs: potential causes and implications for application," Cell Stem Cell, vol. 13, no. 2, pp. 149-159, 2013.

[96] M. Hofmann, K. C. Wollert, G. P. Meyer et al., "Monitoring of bone marrow cell homing into the infarcted human myocardium," Circulation, vol. 111, no. 17, pp. 2198-2202, 2005.

[97] M. Z. Ratajczak, M. Kucia, T. Jadczyk et al., "Pivotal role of paracrine effects in stem cell therapies in regenerative medicine: can we translate stem cell-secreted paracrine factors and microvesicles into better therapeutic strategies," Leukemia, vol. 26, no. 6, pp. 1166-1173, 2012.

[98] G. Maguire, "Stem cell therapy without the cells," Communicative \& Integrative Biology, vol. 6, no. 6, Article ID e26631, 2013.

[99] S. M. Chacko, M. Khan, M. L. Kuppusamy et al., "Myocardial oxygenation and functional recovery in infarct rat hearts transplanted with mesenchymal stem cells," The American Journal of Physiology-Heart and Circulatory Physiology, vol. 296, no. 5, pp. H1263-H1273, 2009.

[100] Y. Imanishi, A. Saito, H. Komoda et al., "Allogenic mesenchymal stem cell transplantation has a therapeutic effect in acute myocardial infarction in rats," Journal of Molecular and Cellular Cardiology, vol. 44, no. 4, pp. 662-671, 2008.

[101] D. C. Vela, G. V. Silva, J. A. R. Assad et al., "Histopathological study of healing after allogenic mesenchymal stem cell delivery in myocardial infarction in dogs," Journal of Histochemistry and Cytochemistry, vol. 57, no. 2, pp. 167-176, 2009.

[102] R. R. Makkar, M. J. Price, M. Lill et al., "Intramyocardial injection of allogenic bone marrow-derived mesenchymal stem cells without immunosuppression preserves cardiac function in a porcine model of myocardial infarction," Journal of Cardiovascular Pharmacology and Therapeutics, vol. 10, no. 4, pp. 225-233, 2005.

[103] L. V. Kursova, A. G. Konoplyannikov, S. S. Kal'sina, and S. B. Baboyan, "Allogenic cardiomyoblasts raised from human mesenchymal stem cells in the therapy of radiation cardiomyopathy and pericarditis: case report," Bulletin of Experimental Biology and Medicine, vol. 157, no. 1, pp. 143-145, 2014.

[104] R. R. U. Smith, E. Marban, and L. Marban, "Enhancing retention and efficacy of cardiosphere-derived cells administered after 
myocardial infarction using a hyaluronan-gelatin hydrogel," Biomatter, vol. 3, no. 1, Article ID e24490, 2013.

[105] K. Malliaras, T.-S. Li, D. Luthringer et al., "Safety and efficacy of allogeneic cell therapy in infarcted rats transplanted with mismatched cardiosphere-derived cells," Circulation, vol. 125, no. 1, pp. 100-112, 2012.

[106] M. Drukker, H. Katchman, G. Katz et al., "Human embryonic stem cells and their differentiated derivatives are less susceptible to immune rejection than adult cells," Stem Cells, vol. 24, no. 2, pp. 221-229, 2006.

[107] M. Drukker, G. Katz, A. Urbach et al., "Characterization of the expression of MHC proteins in human embryonic stem cells," Proceedings of the National Academy of Sciences of the United States of America, vol. 99, no. 15, pp. 9864-9869, 2002.

[108] C. Bocelli-Tyndall, E. Trella, A. Frachet et al., "FGF2 induces RANKL gene expression as well as IL1 $\beta$ regulated MHC class II in human bone marrow-derived mesenchymal progenitor stromal cells," Annals of the Rheumatic Diseases, vol. 74, no. 1, pp. 260-266, 2015.

[109] C. Bocelli-Tyndall, P. Zajac, N. Di Maggio et al., "Fibroblast growth factor 2 and platelet-derived growth factor, but not platelet lysate, induce proliferation-dependent, functional class II major histocompatibility complex antigen in human mesenchymal stem cells," Arthritis and Rheumatism, vol. 62, no. 12, pp. 3815-3825, 2010.

[110] P. Lohan, C. M. Coleman, J. M. Murphy, M. D. Griffin, T. Ritter, and A. E. Ryan, "Changes in immunological profile of allogeneic mesenchymal stem cells after differentiation: should we be concerned?" Stem Cell Research \& Therapy, vol. 5, article 99, 2014.

[111] J. L. Zakrzewski, M. R. M. van den Brink, and J. A. Hubbell, "Overcoming immunological barriers in regenerative medicine," Nature Biotechnology, vol. 32, no. 8, pp. 786-794, 2014.

[112] R. Al-Daccak and D. Charron, "Allogenic benefit in stem cell therapy: cardiac repair and regeneration," Tissue Antigens, vol. 86, no. 3, pp. 155-162, 2015.

[113] B. Zhou, Q. Ma, S. Rajagopal et al., "Epicardial progenitors contribute to the cardiomyocyte lineage in the developing heart," Nature, vol. 454, no. 7200, pp. 109-113, 2008.

[114] A. Leri, J. Kajstura, and P. Anversa, "Cardiac stem cells and mechanisms of myocardial regeneration," Physiological Reviews, vol. 85, no. 4, pp. 1373-1416, 2005.

[115] K. Urbanek, D. Cesselli, M. Rota et al., "Stem cell niches in the adult mouse heart," Proceedings of the National Academy of Sciences of the United States of America, vol. 103, no. 24, pp. 9226-9231, 2006.

[116] F. Limana, A. Germani, A. Zacheo et al., "Exogenous highmobility group box 1 protein induces myocardial regeneration after infarction via enhanced cardiac C-kit ${ }^{+}$cell proliferation and differentiation," Circulation research, vol. 97, no. 8, pp. e73e83, 2005.

[117] C. Bielmann, S. Rignault-Clerc, L. Liaudet et al., "Brain natriuretic peptide is able to stimulate cardiac progenitor cell proliferation and differentiation in murine hearts after birth," Basic Research in Cardiology, vol. 110, article 455, 2015.

[118] V. Dayan, G. Yannarelli, F. Billia et al., "Mesenchymal stromal cells mediate a switch to alternatively activated monocytes/macrophages after acute myocardial infarction," Basic Research in Cardiology, vol. 106, no. 6, pp. 1299-1310, 2011.
[119] T. Nishikimi, K. Kuwahara, and K. Nakao, "Current biochemistry, molecular biology, and clinical relevance of natriuretic peptides," Journal of Cardiology, vol. 57, no. 2, pp. 131-140, 2011.

[120] L. R. Potter, A. R. Yoder, D. R. Flora, L. K. Antos, and D. M. Dickey, "Natriuretic peptides: their structures, receptors, physiologic functions and therapeutic applications," in cGMP: Generators, Effectors and Therapeutic Implications, vol. 191 of Handbook of Experimental Pharmacology, pp. 341-366, Springer, Berlin, Germany, 2009.

[121] A. Clerico, S. Vittorini, and C. Passino, "Circulating forms of the b-type natriuretic peptide prohormone: pathophysiologic and clinical considerations," Advances in Clinical Chemistry, vol. 58, pp. 31-44, 2012.

[122] E. Morita, H. Yasue, M. Yoshimura et al., "Increased plasma levels of brain natriuretic peptide in patients with acute myocardial infarction," Circulation, vol. 88, no. 1, pp. 82-91, 1993.

[123] F. Liang, J. O’Rear, U. Schellenberger et al., "Evidence for functional heterogeneity of circulating B-type natriuretic peptide," Journal of the American College of Cardiology, vol. 49, no. 10, pp. 1071-1078, 2007.

[124] H. H. Chen, "Heart failure: a state of brain natriuretic peptide deficiency or resistance or both!", Journal of the American College of Cardiology, vol. 49, no. 10, pp. 1089-1091, 2007.

[125] A. H. Bruggink, N. de Jonge, M. F. M. van Oosterhout et al., "Brain natriuretic peptide is produced both by cardiomyocytes and cells infiltrating the heart in patients with severe heart failure supported by a left ventricular assist device," Journal of Heart and Lung Transplantation, vol. 25, no. 2, pp. 174-180, 2006.

[126] E. M. Abdelalim and I. Tooyama, "BNP signaling is crucial for embryonic stem cell proliferation," PLoS ONE, vol. 4, no. 4, Article ID e5341, 2009.

[127] M. Kuhn, K. Völker, K. Schwarz et al., "The natriuretic peptide/guanylyl cyclase-a system functions as a stress-responsive regulator of angiogenesis in mice," Journal of Clinical Investigation, vol. 119, no. 7, pp. 2019-2030, 2009.

[128] K. Kuwahara and K. Nakao, "Regulation and significance of atrial and brain natriuretic peptides as cardiac hormones," Endocrine Journal, vol. 57, no. 7, pp. 555-565, 2010.

[129] S. P. D'Souza and G. F. Baxter, "B type natriuretic peptide: a good omen in myocardial ischaemia?" Heart, vol. 89, no. 7, pp. 707709, 2003.

[130] B. Ren, Y. Shen, H. Shao, J. Qian, H. Wu, and H. Jing, "Brain natriuretic peptide limits myocardial infarct size dependent of nitric oxide synthase in rats," Clinica Chimica Acta, vol. 377, no. 1-2, pp. 83-87, 2007.

[131] D. S. Burley and G. F. Baxter, "B-type natriuretic peptide at early reperfusion limits infarct size in the rat isolated heart," Basic Research in Cardiology, vol. 102, no. 6, pp. 529-541, 2007.

[132] B. Wu, H. Jiang, R. Lin, B. Cui, H. Wen, and Z. Lu, "Pretreatment with $\mathrm{B}$-type natriuretic peptide protects the heart from ischemia-reperfusion injury by inhibiting myocardial apoptosis," Tohoku Journal of Experimental Medicine, vol. 219, no. 2, pp. 107-114, 2009.

[133] A.-M. Moilanen, J. Rysä, E. Mustonen et al., "Intramyocardial BNP gene delivery improves cardiac function through distinct context-dependent mechanisms," Circulation: Heart Failure, vol. 4, no. 4, pp. 483-495, 2011.

[134] A. Cataliotti, J. M. Tonne, D. Bellavia et al., "Long-term cardiac pro-B-type natriuretic peptide gene delivery prevents the development of hypertensive heart disease in spontaneously hypertensive rats," Circulation, vol. 123, no. 12, pp. 1297-1305, 2011. 
[135] N. Glezeva, P. Collier, V. Voon et al., "Attenuation of monocyte chemotaxis-a novel anti-inflammatory mechanism of action for the cardio-protective hormone B-type natriuretic peptide," Journal of Cardiovascular Translational Research, vol. 6, no. 4, pp. 545-557, 2013.

[136] S. M. Shaw, J. E. Fildes, C. M. Puchałka, M. Basith, N. Yonan, and S. G. Williams, "BNP directly immunoregulates the innate immune system of cardiac transplant recipients in vitro," Transplant Immunology, vol. 20, no. 3, pp. 199-202, 2009.

[137] V. Chiurchiù, V. Izzi, F. D’Aquilio, F. Carotenuto, P. Di Nardo, and P. M. Baldini, "Brain Natriuretic Peptide (BNP) regulates the production of inflammatory mediators in human THP-1 macrophages," Regulatory Peptides, vol. 148, no. 1-3, pp. 26-32, 2008.

[138] R. Kawakami, Y. Saito, I. Kishimoto et al., "Overexpression of brain natriuretic peptide facilitates neutrophil infiltration and cardiac matrix metalloproteinase- 9 expression after acute myocardial infarction," Circulation, vol. 110, no. 21, pp. 33063312, 2004.

[139] B. B. Das, S. Raj, and R. Solinger, "Natriuretic peptides in cardiovascular diseases of fetus, infants and children," Cardiovascular \& Hematological Agents in Medicinal Chemistry, vol. 7, no. 1, pp. 43-51, 2009.

[140] V. A. Cameron and L. J. Ellmers, "Minireview: natriuretic peptides during development of the fetal heart and circulation," Endocrinology, vol. 144, no. 6, pp. 2191-2194, 2003.

[141] J. R. Becker, S. Chatterjee, T. Y. Robinson et al., "Differential activation of natriuretic peptide receptors modulates cardiomyocyte proliferation during development," Development, vol. 141, no. 2, pp. 335-345, 2014.

[142] V. A. Cameron, G. D. Aitken, L. J. Ellmers, M. A. Kennedy, and E. A. Espiner, "The sites of gene expression of atrial, brain, and C-type natriuretic peptides in mouse fetal development: temporal changes in embryos and placenta," Endocrinology, vol. 137, no. 3, pp. 817-824, 1996.

[143] L. Schwachtgen, M. Herrmann, T. Georg, P. Schwarz, N. Marx, and A. Lindinger, "Reference values of NT-proBNP serum concentrations in the umbilical cord blood and in healthy neonates and children," Zeitschrift für Kardiologie, vol. 94, no. 6, pp. 399-404, 2005.

[144] J. M. Tonne, J. M. Campbell, A. Cataliotti et al., "Secretion of glycosylated pro-B-type natriuretic peptide from normal cardiomyocytes," Clinical Chemistry, vol. 57, no. 6, pp. 864-873, 2011.

[145] J. Peng, J. Jiang, W. Wang, X. Qi, X.-L. Sun, and Q. Wu, "Glycosylation and processing of pro-B-type natriuretic peptide in cardiomyocytes," Biochemical and Biophysical Research Communications, vol. 411, no. 3, pp. 593-598, 2011.

[146] N. J. A. Scott, L. J. Ellmers, J. G. Lainchbury et al., "Influence of natriuretic peptide receptor-1 on survival and cardiac hypertrophy during development," Biochimica et Biophysica ActaMolecular Basis of Disease, vol. 1792, no. 12, pp. 1175-1184, 2009.

[147] E. M. Abdelalim and I. Tooyama, "NPR-A regulates selfrenewal and pluripotency of embryonic stem cells," Cell Death \& Disease, vol. 2, no. 3, article el27, 2011.

[148] L. J. Ellmers, N. J. A. Scott, J. Piuhola et al., "Nprl-regulated gene pathways contributing to cardiac hypertrophy and fibrosis," Journal of Molecular Endocrinology, vol. 38, no. 1-2, pp. 245-257, 2007.

[149] J. W. Knowles, G. Esposito, L. Mao et al., "Pressure-independent enhancement of cardiac hypertrophy in natriuretic peptide receptor A-deficient mice," The Journal of Clinical Investigation, vol. 107, no. 8, pp. 975-984, 2001.

[150] I. Kishimoto, T. Tokudome, T. Horio, D. L. Garbers, K. Nakao, and K. Kangawa, "Natriuretic peptide signaling via guanylyl cyclase (GC)-A: an endogenous protective mechanism of the heart," Current Cardiology Reviews, vol. 5, no. 1, pp. 45-51, 2009.

[151] C. Sogawa, A. Abe, T. Tsuji, M. Koizumi, T. Saga, and T. Kunieda, "Gastrointestinal tract disorder in natriuretic peptide receptor B gene mutant mice," The American Journal of Pathology, vol. 177, no. 2, pp. 822-828, 2010.

[152] C. Sogawa, T. Tsuji, Y. Shinkai, K. Katayama, and T. Kunieda, "Short-limbed dwarfism: slw is a new allele of Npr2 causing chondrodysplasia," The Journal of Heredity, vol. 98, no. 6, pp. 575-580, 2007.

[153] N. Tamura, L. K. Doolittle, R. E. Hammer, J. M. Shelton, J. A. Richardson, and D. L. Garbers, "Critical roles of the guanylyl cyclase B receptor in endochondral ossification and development of female reproductive organs," Proceedings of the National Academy of Sciences of the United States of America, vol. 101, no. 49, pp. 17300-17305, 2004.

[154] C. Sogawa, Y. Fujiwara, S. Tsukamoto et al., "Mutant phenotype analysis suggests potential roles for C-type natriuretic peptide receptor (NPR-B) in male mouse fertility," Reproductive Biology and Endocrinology, vol. 12, article 64, 2014.

[155] K. A. Geister, M. L. Brinkmeier, M. Hsieh et al., "A novel lossof-function mutation in Npr2 clarifies primary role in female reproduction and reveals a potential therapy for acromesomelic dysplasia, Maroteaux type," Human Molecular Genetics, vol. 22, no. 2, pp. 345-357, 2013.

[156] T. H. Langenickel, J. Buttgereit, I. Pagel-Langenickel et al., "Cardiac hypertrophy in transgenic rats expressing a dominantnegative mutant of the natriuretic peptide receptor B," Proceedings of the National Academy of Sciences of the United States of America, vol. 103, no. 12, pp. 4735-4740, 2006.

[157] T. Ahmad and G. M. Felker, "Subcutaneous B-type natriuretic peptide for treatment of heart failure: a dying therapy reborn?" Journal of the American College of Cardiology, vol. 60, no. 22, pp. 2313-2315, 2012.

[158] C. Partovian, S.-X. Li, X. Xu et al., "Patterns of change in nesiritide use in patients with heart failure: how hospitals react to new information," JACC: Heart Failure, vol. 1, no. 4, pp. 318324,2013

[159] S. S. Gottlieb, A. Stebbins, A. A. Voors et al., "Effects of nesiritide and predictors of urine output in acute decompensated heart failure: results from ASCEND-HF (acute study of clinical effectiveness of nesiritide and decompensated heart failure)," Journal of the American College of Cardiology, vol. 62, no. 13, pp. 1177-1183, 2013.

[160] C. M. O'Connor, R. C. Starling, A. F. Hernandez et al., "Effect of nesiritide in patients with acute decompensated heart failure," The New England Journal of Medicine, vol. 365, no. 1, pp. 32-43, 2011.

[161] H. H. Chen, F. L. Martin, R. J. Gibbons et al., "Low-dose nesiritide in human anterior myocardial infarction suppresses aldosterone and preserves ventricular function and structure: a proof of concept study," Heart, vol. 95, no. 16, pp. 1315-1319, 2009.

[162] H. H. Chen, J. F. Glockner, J. A. Schirger, A. Cataliotti, M. M. Redfield, and J. C. Burnett Jr., "Novel protein therapeutics for systolic heart failure: chronic subcutaneous B-type natriuretic peptide," Journal of the American College of Cardiology, vol. 60, no. 22, pp. 2305-2312, 2012. 
[163] T. Lyu, Y. Zhao, T. Zhang et al., "Natriuretic peptides as an adjunctive treatment for acute myocardial infarction," International Heart Journal, vol. 55, no. 1, pp. 8-16, 2014.

[164] S. J. Sangaralingham, J. C. Burnett Jr., P. M. McKie, J. A. Schirger, and H. H. Chen, "Rationale and design of a randomized, double-blind, placebo-controlled clinical trial to evaluate the efficacy of B-type natriuretic peptide for the preservation of left ventricular function after anterior myocardial infarction," Journal of Cardiac Failure, vol. 19, no. 8, pp. 533-539, 2013.

[165] J. J. V. McMurray, M. Packer, A. S. Desai et al., "Angiotensinneprilysin inhibition versus enalapril in heart failure," The New England Journal of Medicine, vol. 371, no. 11, pp. 993-1004, 2014.

[166] M. Packer, J. J. McMurray, A. S. Desai et al., "Angiotensin receptor neprilysin inhibition compared with enalapril on the risk of clinical progression in surviving patients with heart failure," Circulation, vol. 131, no. 1, pp. 54-61, 2015.

[167] W. Jiang, D.-Y. Cai, C.-S. Pan et al., "Changes in production and metabolism of brain natriuretic peptide in rats with myocardial necrosis," European Journal of Pharmacology, vol. 507, no. 1-3, pp. 153-162, 2005.

[168] Y. Hirata, H. Hayakawa, E. Suzuki, and M. Omata, "Does endothelin work as an intrarenal mechanism to alter pressure natriuresis in spontaneously hypertensive rats?" Journal of Hypertension, vol. 12, no. 3, pp. 251-257, 1994.

[169] J. Xu, O. A. Carretero, Y.-H. Liu et al., "Dual inhibition of ACE and NEP provides greater cardioprotection in mice with heart failure," Journal of Cardiac Failure, vol. 10, no. 1, pp. 83-89, 2004.

[170] T. G. von Lueder, B. H. Wang, A. R. Kompa et al., "Angiotensin receptor neprilysin inhibitor LCZ696 attenuates cardiac remodeling and dysfunction after myocardial infarction by reducing cardiac fibrosis and hypertrophy," Circulation: Heart Failure, vol. 8, no. 1, pp. 71-78, 2015.

[171] A. S. Jaffe, "Unwinding the interaction of natriuretic peptides and neprilysin," Journal of the American College of Cardiology, vol. 65, no. 7, pp. 666-667, 2015.

[172] J. C. Garbern and R. T. Lee, "Cardiac stem cell therapy and the promise of heart regeneration," Cell Stem Cell, vol. 12, no. 6, pp. 689-698, 2013.

[173] S. A. Doppler, M.-A. Deutsch, R. Lange, and M. Krane, "Cardiac regeneration: current therapies-future concepts," Journal of Thoracic Disease, vol. 5, no. 5, pp. 683-697, 2013.

[174] S.-Y. Liao and H.-F. Tse, "Multipotent (adult) and pluripotent stem cells for heart regeneration: what are the pros and cons?" Stem Cell Research \& Therapy, vol. 4, article 151, 2013. 

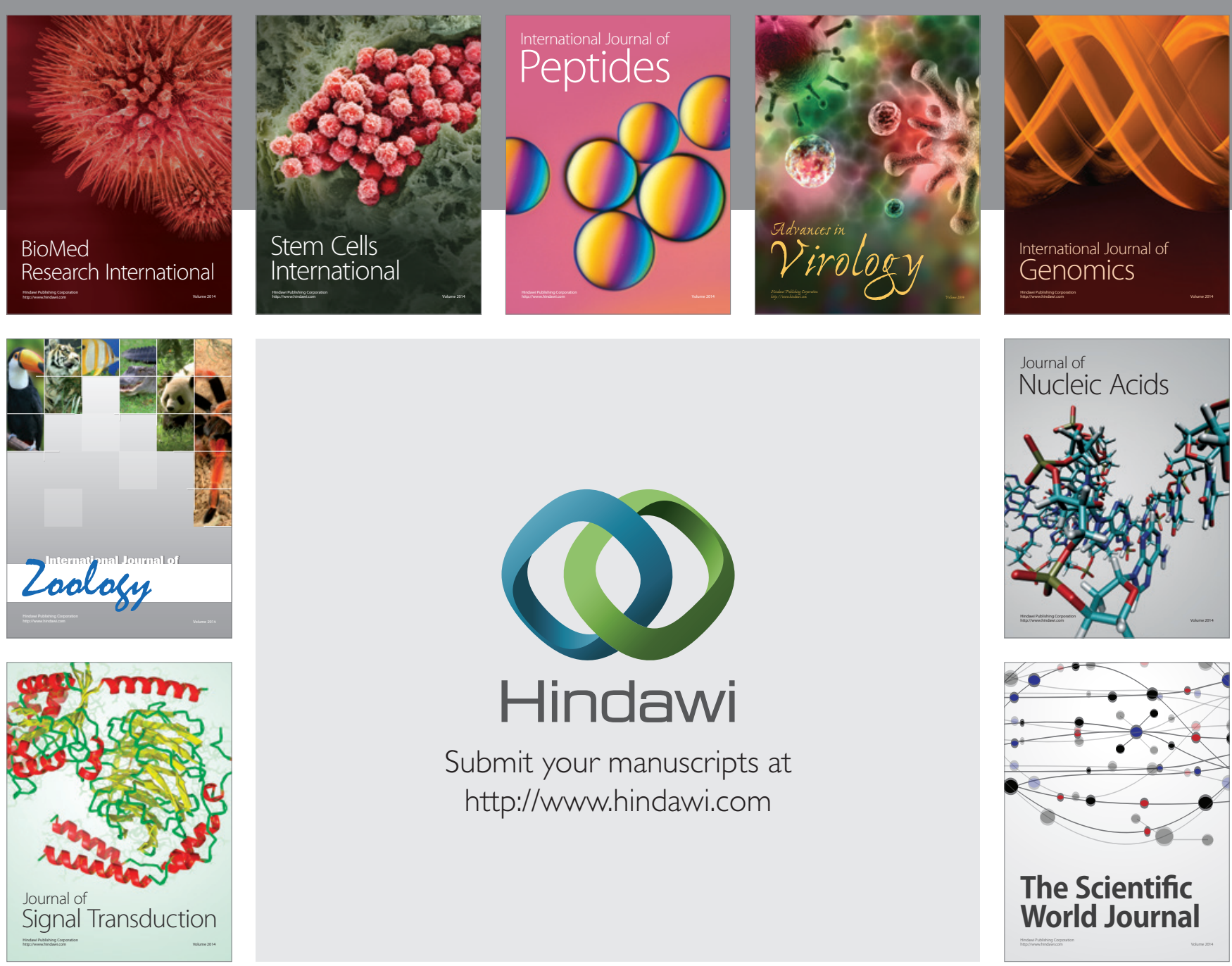

Submit your manuscripts at

http://www.hindawi.com
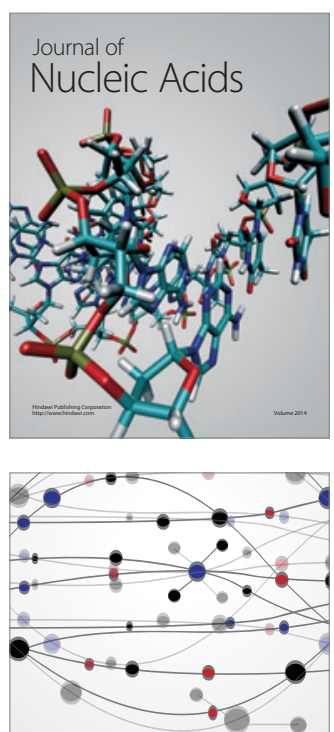

The Scientific World Journal
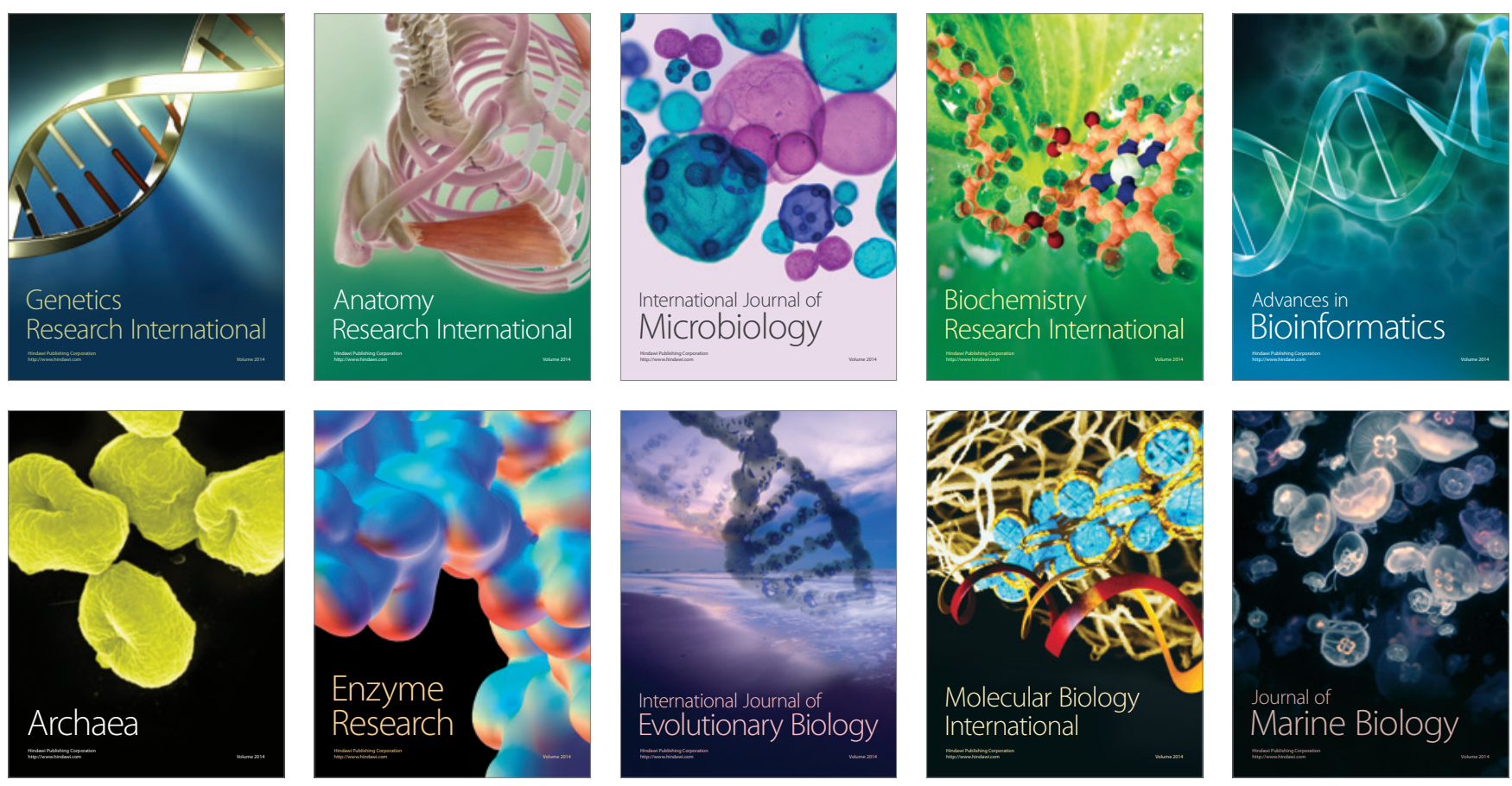